\title{
Applying Nanomaterials to Modern Biomedical Electrochemical Detection of Metabolites, Electrolytes, and Pathogens
}

\author{
Itthipon Jeerapan ${ }^{1,2}, * \mathbb{C}$, Thitaporn Sonsa-ard ${ }^{3,4}$ and Duangjai Nacapricha ${ }^{3,4}$ \\ 1 Division of Physical Science, Faculty of Science, Prince of Songkla University, Hat Yai, \\ Songkhla 90112, Thailand \\ 2 Center of Excellence for Trace Analysis and Biosensor, Prince of Songkla University, Hat Yai, \\ Songkhla 90112, Thailand \\ 3 Department of Chemistry and Center of Excellence for Innovation in Chemistry, Faculty of Science, \\ Mahidol University, Bangkok 10400, Thailand; t.sonsa.ard@gmail.com (T.S.-a.); \\ duangjai.nac@mahidol.ac.th (D.N.) \\ 4 Flow Innovation-Research for Science and Technology Laboratories (Firstlabs), Bangkok 10400, Thailand \\ * Correspondence: itthipon.j@psu.ac.th or ijeerapa@ucsd.edu
}

Received: 6 June 2020; Accepted: 13 August 2020; Published: 19 August 2020

\begin{abstract}
Personal biosensors and bioelectronics have been demonstrated for use in out-of-clinic biomedical devices. Such modern devices have the potential to transform traditional clinical analysis into a new approach, allowing patients or users to screen their own health or warning of diseases. Researchers aim to explore the opportunities of easy-to-wear and easy-to-carry sensors that would empower users to detect biomarkers, electrolytes, or pathogens at home in a rapid and easy way. This mobility would open the door for early diagnosis and personalized healthcare management to a wide audience. In this review, we focus on the recent progress made in modern electrochemical sensors, which holds promising potential to support point-of-care technologies. Key original research articles covered in this review are mainly experimental reports published from 2018 to 2020. Strategies for the detection of metabolites, ions, and viruses are updated in this article. The relevant challenges and opportunities of applying nanomaterials to support the fabrication of new electrochemical biosensors are also discussed. Finally, perspectives regarding potential benefits and current challenges of the technology are included. The growing area of personal biosensors is expected to push their application closer to a new phase of biomedical advancement.
\end{abstract}

Keywords: nanomaterials; wearable sensors; electrochemical sensors; glucose; viruses; miniaturized sensors; bioelectronics; point-of-care technology; personalized healthcare

\section{Introduction}

Smart healthcare is a new class of systems transforming a traditional healthcare service to modern platforms, integrating state-of-the-art technology, e.g., wearable sensors, portable electronic systems, digital biodevices, and internet networks to connect users with healthcare services. The research area aiming to develop modern systems for smart healthcare applications has been expanding at an accelerating rate [1-3]. Limitations to accessing health services, particularly under difficult circumstances, such as a pandemic, may also accelerate the development in easy-to-use and out-of-clinic biosensors [4]. Several wearable sensors that give exciting opportunities to monitor personal physiological parameters, such as body movement [5], eye movement [6], blood pressure [7,8], heart rate [9,10], body temperature [11,12], and respiratory rate [13,14], have been developed. However, another important group of sensors providing complementary data of significant chemical and biochemical markers is attracting attention $[15,16]$. 
Extending from recent review articles [17-20], this review will focus on very recent strategies used to realize biomedical electrochemical sensors by applying nanomaterials and functional materials for the detection of metabolites, electrolytes, and pathogens. Modern healthcare requires new solutions for achieving quick, easy-to-use, and fit-to-lifestyle devices that can provide early warning to the user of health issues, ensuring health security and effective management. Importantly, miniaturized biosensors are suitable candidates that can be integrated for early clinical diagnosis, prevention of illnesses, and maintenance of personal wellbeing [21-23]. Such integrations with smartphones and portable/wearable devices could enhance the convenience of smart biomedical sensing systems.

Two main platforms, including easy-to-wear and easy-to-carry sensing devices, are emphasized in this review (Figure 1). The recent progress in developing sensors for measuring metabolites and electrolytes (such as glucose, lactate, ions, etc.) will be highlighted along with relevant technological factors. The most common example of point-of-care detection is glucose monitoring because irregular glucose metabolism links to several problems, including diabetes, hyperglycemia, and hypoglycemia, etc. [24-26]. The development of miniaturized and simple biosensors allows the transition of traditional blood testing in hospitals to self-testing at homes. Furthermore, ongoing efforts have contributed more and more to the advancement of wearable, noninvasive, or minimally invasive platforms. Such new directions aim to address old obstacles, such as inconvenient and discontinuous monitoring. Modern strategies of the out-of-clinic analysis would support a new way to realize fast and actionable feedback and personalized healthcare management. In addition to sensors monitoring metabolites and electrolytes, the early detection of pathogens (such as viruses) is another crucial area [27-30]. Remarkably, the recent global problem pertaining to the pandemic (due to the novel coronavirus, COVID-19) leads to tremendous interest in bioassay research [31,32]. Clearly, the research on modern biosensors and bioelectronics that can provide rapid detection is becoming more important. The speedy screening of the pathogenic infection would help patients to quickly access the right medical services, avoiding severe complications. This provides significant benefits to the vast population to slow down the spreading of contagious pathogens.

Advanced material functionalization is one of the most vital factors for advancing innovative devices for the new analytical chemistry (Figure 1A) [33-36]. The nanomaterial-based electrochemical transducer would contribute to the fabrication of effective sensors and greatly maximize functional densities of miniaturized systems. Moreover, nanomaterial surfaces can also be tailored to form specific functions, structures, or desirable functional groups [37-39]. These are crucial for the immobilization of biorecognition layers on the nanomaterial-base electrodes (Figure 1B,C) [40]. Opportunities to take advantages of nanomaterials as well as related challenges will be discussed in this review. In addition to the electronic system, the main components in the electrochemical sensor include the transducer and the bioreceptor layer (or sensitive layer). These are required to fabricate an effective layer that can specifically interact with the target (e.g., glucose) and involve a biological event or a reaction to yield a highly sensitive signal. An example that combines the advantages of functional nanomaterials and composites to improve the sensitivity of the electrochemical sensor is shown in Figure 2. In this example, due to the three-dimensional (3D) porous structure of the graphite foam and the heteroatom doping, the sensor displays a favorable rate of electron transfer, and provides a large surface area, allowing loading of a number of biomolecules (such as glucose oxidase (GOx) enzymes, which involves the selective electrooxidation of the glucose target) [41]. Prussian Blue (PB) is also added to serve as one of the most effective electrocatalyst for $\mathrm{H}_{2} \mathrm{O}_{2}$. Note that $\mathrm{H}_{2} \mathrm{O}_{2}$ is a common byproduct of many enzymatic-catalyzed reactions. Such an advantage to electrochemically sense $\mathrm{H}_{2} \mathrm{O}_{2}$ empowers the nanomaterial-based sensor to be applied to many biosensing applications. Several biosensors, such as hydrogen peroxide [42,43], glucose [44,45], lactate, and alcohol sensors [46,47], employ PB. PB represents a key material to provide functions of the redox mediator or the 'artificial peroxidase' electrocatalyst. Advantageously, PB can allow the biosensing system to operate at a low detection potential [41,48-50]. Nonetheless, related challenges should be highlighted. For example, in biological systems, electrolytes (e.g., $\mathrm{H}+$ or $\mathrm{K}+$ in sweat) can fluctuate. Such dynamic variation can vary the electrochemical signal of PB-based sensors or impair the PB framework [51-53]. This 
challenge is an example to show that the design of the electrochemical transducer should be a primary consideration that requires engineers to optimize properties of materials [54-56]. Stability of the material is another example of a parameter when developing nanomaterial-based sensors. For instance, the electrosynthesis of inorganic frameworks, e.g., PB, using different approaches display different qualities. The PB synthesized in chloride solutions provide superior stability compared with synthesis under chloride-free environments [52]. Therefore, efforts have been made to enhance the operational stability of PB-based materials [57]. In addition to these examples, more challenges pertaining to the use of materials in biosensors will be discussed further.

This review will cover some key developments on electrochemical biosensors over the past three years. Key articles considered for eligibility are mainly experimental reports published from 2018 to 2020. Research progress using nanomaterials and contributing to modern electrochemical platforms are highlighted in this article. This aims to cover the accelerating state in the development of modern biomedical electrochemical sensors with relevant obstacles. Finally, conclusions and perspectives will be summarized in the final section.

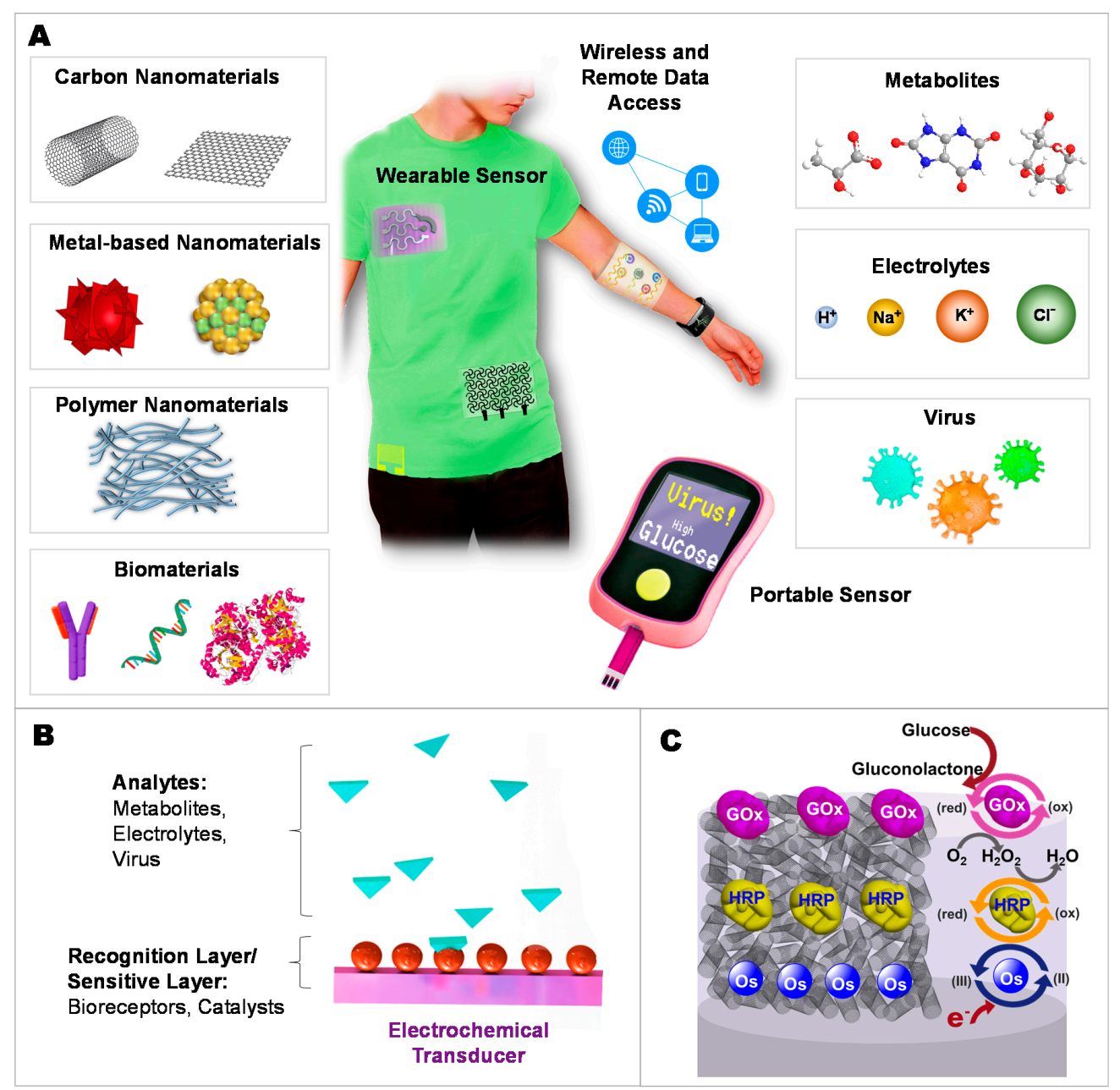

Figure 1. Concepts of out-of-clinic electrochemical biosensors. (A) The main platforms include wearable electrochemical sensors and portable electrochemical sensors. Nanomaterials and recognition biomaterials are important for the development of such modern point-of-care devices. (B) The main components of the electrochemical biosensor. (C) An example of the electrochemical sensor for glucose detection. This consists of glucose oxidase (GOx) as a specific enzyme to catalyze glucose, producing $\mathrm{H}_{2} \mathrm{O}_{2}$. The horseradish peroxidase enzyme (HRP) involves the electrochemical reaction with the generated $\mathrm{H}_{2} \mathrm{O}_{2}$. The mediator is used to shuttle the electron to the electrode surface, allowing the electrochemical signal to be measured. 


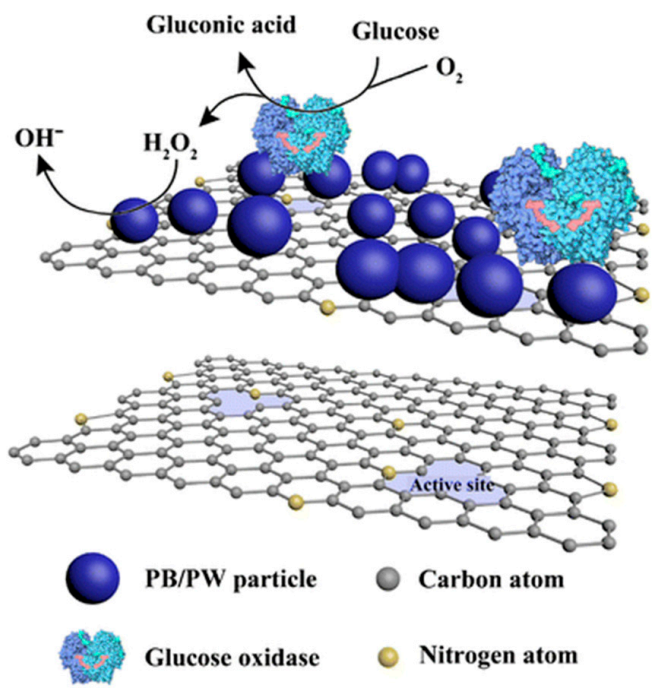

Figure 2. An example of using nanomaterials coupled with Prussian Blue (PB) to develop a PB-based enzymatic biosensor. PB and PW stand for Prussian Blue $\left(\mathrm{Fe}_{4}\left[\mathrm{Fe}(\mathrm{CN})_{6}\right]_{3}\right)$ and Prussian White $\left(\mathrm{K}_{4} \mathrm{Fe}_{4}\left[\mathrm{Fe}(\mathrm{CN})_{6}\right]_{3}\right)$. Adapted with permission from [41], copyright 2018, Springer Nature.

\section{Moving toward Modern Electrochemical Detection of Metabolites and Electrolytes}

\subsection{Developing Glucose Sensors}

Modern electrochemical biosensors have been demonstrated as promising tools for supporting smart healthcare as they can detect biomarkers available in body fluids, such as saliva [58,59], interstitial fluid $[60,61]$, and sweat $[62,63]$. The gold-standard biofluid for monitoring glucose is blood. For example, it is well-known that the blood glucose level can be used to warn diabetic patients. Normal blood glucose concentration is around 4.9-6.9 $\mathrm{mM}[64,65]$, while the blood glucose level of patients can be high (even $40 \mathrm{mM}$ ) or low (2 $\mathrm{mM}$ ) [65-68]. In addition to the detection of glucose in blood, glucose levels in other biofluids are interesting. Researchers aim to develop more technological tools to investigate the glucose concentration in alternative biofluids and examine the correlation of such glucose levels with blood glucose level $[69,70]$. Concentration ranges of glucose in alternative fluids are around 0.006-2 mM (sweat) [71-73], 3.9-6.6 (interstitial fluid) [74], 2.78-5.56 mM (urine) [75,76], and $0.03-1.39 \mathrm{mM}$ (saliva) $[64,65,77,78]$. The use of nanomaterials is important to help the sensor to be able to operate under fluctuating conditions of real biological systems. For instance, engineered nanomaterials can be developed to tailor the desirable electrocatalytic activity while enhancing stability of the sensor. Examples of materials based on copper oxide, tin oxide, or titanium dioxide were reported in patents to build non-enzymatic glucose sensors $[79,80]$. Thanks to their high surface area and favorable electrocatalytic activity of functional nanomaterials, non-enzymatic sensors can be realized. In addition, non-enzymatic biosensors could provide long shelf-life stability, low detection limit, and high sensitivity. Such non-enzymatic sensors have become another important class; the development of this non-enzymatic materials would be an alternative solution to fabricate highly sensitive, stable, non-enzymatic biosensors [81-84]. Additional challenges to achieve an on-body biosensing device are related to long-term storage and stretchability. These factors need to be taken into account when fabricating wearable sensing devices with nanomaterials.

An example to produce a stretchable and wearable non-enzymatic glucose sensor was the formation of nanoporous gold on a 3D micropatterned elastomeric substrate to prevent undergoing brittle fracture of nanoporous gold [85]. As illustrated in Figure 3A, the sensing patch consisted of the biosensor electrodes on the patterned polydimethylsiloxane (PDMS) substrate, PDMS encapsulation layer, capillary cotton layer, and cover layer made of polyurethane nanofiber for attaching to the skin. This design enabled the engineering of a very thin, tough, and stretchable microfluidics-integrated wearable sensor 
suitable for continuous monitoring of sweat glucose levels. Au-Ag alloy, which is a key conductive material, was deposited on the electrode surface by thermal evaporation. The Ag, as a porogen present in the deposited metallic alloy, was dissolved under strong acidic conditions to form nanoporous gold. The layer of cotton fabric not only provided collection of sweat by liquid absorption but also generated capillary flow of the sample toward the sensing electrodes. The layer of polyurethane nanofibers produced by electrospinning reinforced the device to ensure conformability while maintaining the robustness. In analytical studies, the device showed good linearity in the determination of glucose covering concentration range expected in both hypoglycemic and hyperglycemic patients with high sensitivity and acceptable selectivity against ascorbic acid and uric acid. The sensor showed high stretchability and durability as there were no significant change in sensitivity and analytical output after the device was stretched at 0-30\% strain. The performance was stable after stretching 1000 times (at $30 \%$ strain). The device embedded with the capillary cotton facilitated sample handling and continuous flowing of the testing solution. For the on-body test, signals obtained from glucose monitoring before and after meals were clearly different after the detection chamber was wetted by 10 min of cycling. The device could be conducted over long periods for continuously monitoring sweat glucose. However, the glucose concentrations obtained from the developed device must be normalized with sweat $\mathrm{pH}$ before being compared with those obtained from the commercial glucose meter and the glucose assay kit.

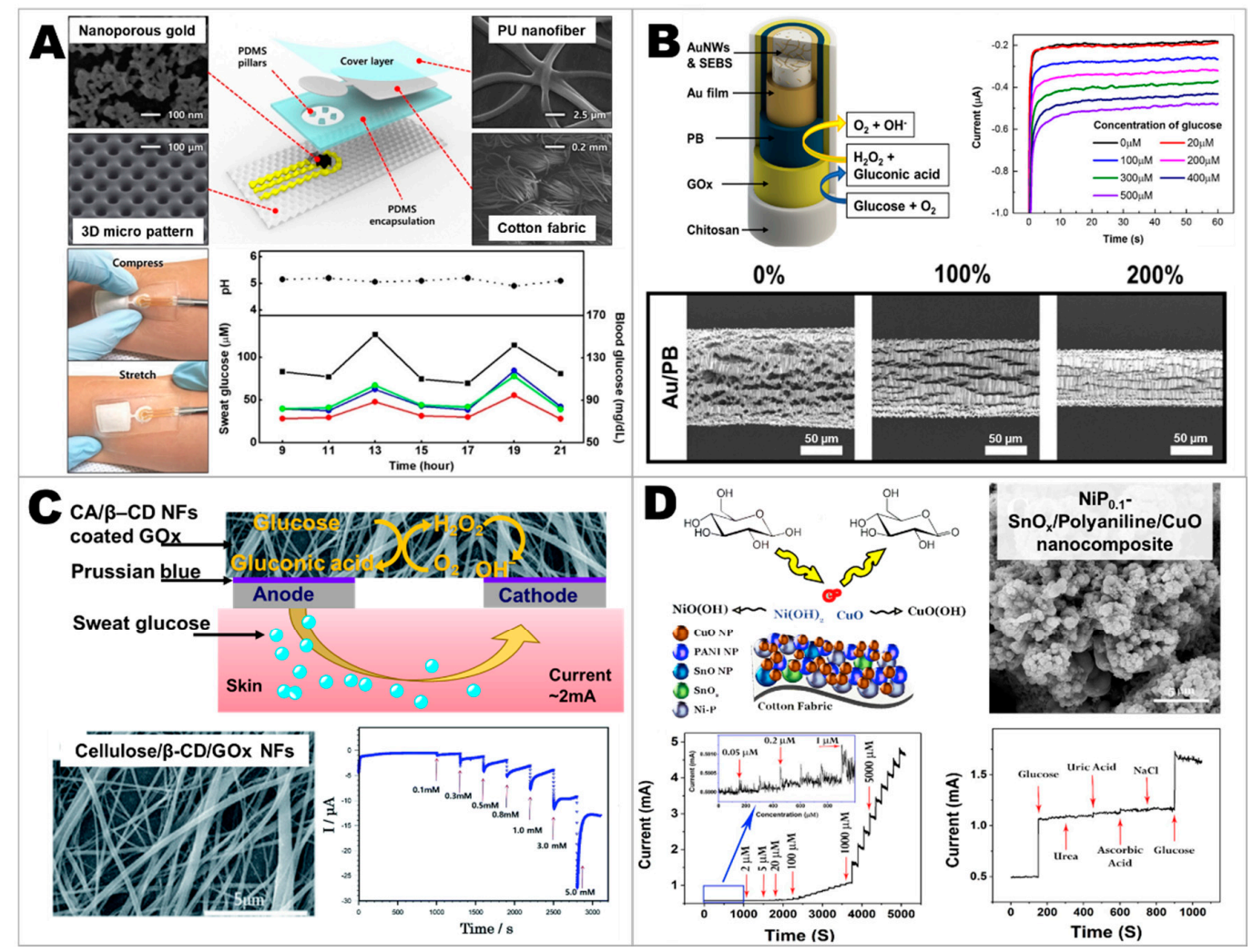

Figure 3. Examples of glucose sensors. (A) Wearable stretchable capillary microfluidic non-enzymatic glucose sensors. Adapted with permission from [85], copyright 2019, American Chemical Society. (B) Wearable fiber-based enzymatic glucose sensors. Adapted with permission from [86], copyright 2019, American Chemical Society. (C) Wearable cellulose/ $\beta$-cyclodextrin nanofiber enzymatic glucose sensors. Adapted under the terms and conditions of the CC-BY 3.0 from [61], copyright 2019, Kim et al., published by RSC Adv. (D) Wearable and flexible metal-based catalysts/polyaniline/cotton-based non-enzymatic glucose sensors. Adapted with permission from [87], copyright 2019, Elsevier.

Another example of the use of gold nanomaterials to improve stretchability and conductivity of the enzyme-based fiber-shaped glucose sensor, is shown in Figure 3B [86]. Three gold fiber-based 
electrodes were formed by dry spinning of gold nanowires (AuNWs) together with the elastomer (styrene-ethylene/butylene-styrene). The challenge is how to avoid poor conductivity during the deformation of the device. A technical solution to ensure good conductivity was to plate a gold film on the fiber surface by electroless plating during pre-stretching of the fiber. After coating with gold film, the fibers were released to its original length. Electrodeposition was utilized to deposit $\mathrm{Ag} / \mathrm{AgCl}$ or PB onto the fiber to serve as reference or working electrodes, respectively. The working electrode was further immobilized with glucose oxidase (GOx) and chitosan. The unmodified Au fiber was used as the counter-electrode. All of these electrodes were helically twined on their individual elastic core and finally patterned to achieve the glucose sensing textile. With this engineering strategy, the conductivity of the fiber electrode could be maintained even at high stretching (at 200\% strain). Besides high sensitivity and selectivity, the fiber-base sensor could be used continuously and displayed stable amperometric signals for $6 \mathrm{~h}$. This was effective to monitor the change in the sweat glucose level before/after a meal. However, the stability of the device was limited by only three-day storage owing to the limited stability of the enzyme. In addition to glucose sensing applications, the idea of using metallic nanowires is versatile with respect to being adapted for other applications in electroanalysis, such as the detection of electrolytes [88]. More examples of the development of electrolyte biosensors will be discussed further in Section 2.3.

Cellulose/ $\beta$-cyclodextrin ( $\beta$-CD) nanofiber was used as matrix for enzyme immobilization on the electrode for developing a glucose sensor patch (Figure 3C) [61]. The cellulose/ $\beta$-CD nanofiber electrode was fabricated by electrospinning cellulose acetate and $\beta-C D$ onto nonwoven cellulose. Converting cellulose acetate into cellulose was done by introducing $\mathrm{NaOH}$ vapor for $20 \mathrm{~h}$. Finally, GOx was immobilized by using the physical absorption method via cross-linking through a host-guest chemical reaction with CD [89]. The $\beta$-CD nanofiber-based electrode immobilized with GOx and the mediator yielded good bioelectrochemical performances with favorable electron transfer and diffusion coefficient of $9.0 \times 10^{-5} \mathrm{~cm}^{2} \mathrm{~s}^{-1}$. The sensor provided high sensitivity for the detection of glucose in the range of $0-1 \mathrm{mM}$.

Metal nanocomposites with conducting polymers are also interesting as they provide good conductivity and flexibility for the development of wearable and flexible electrochemical biosensors. For instance, Ni-based nanoparticles have been considered as providing good redox behaviors, high surface area, and conductivity to the electrode [90-92]. Nickel phosphide (NiP) and copper oxide $(\mathrm{CuO})$ nanoparticles could be synthesized and deposited on the cotton fabric substrate via the chemical method and using polyaniline conducting polymer as a supporting holder to develop a flexible glucose sensor, as shown in Figure 3D [87]. It should be noted that the cotton fabric used as a substrate did not only allow flexibility of the sensor, but also maximize the entrapment of electrocatalytic nanoparticles, yielding enhanced sensitivity. Moreover, the porosity could also contribute to a fast sensing response. Electrooxidation of glucose could be catalyzed by $\mathrm{CuO}$ and NiP nanomaterials in alkaline conditions, resulting in clear oxidation current when increasing the glucose concentrations. The developed sensor delivered high sensitivity and wide range for glucose determination (0.001-1 mM glucose), covering the glucose level in body fluids including blood. Since no enzyme was used, it avoids the limited intrinsic long-term instability of biocatalysts.

\subsection{Developing Lactate Sensors}

The main development of wearable sensors has focused on attaching the sensor directly to the skin, which may cause an unstable electrical contact due to movement. An alternative is to integrate the device with stable and rigid support. This would help to optimize the signal-to-noise result. An example is to mount the printed thick-film electrochemical transducer with the eyeglass frame [93]. The working electrode was modified by drop-casting a mixture of Os-complex mediator solution, carboxy-functionalized multiwalled carbon nanotubes (MWCNTs), horseradish peroxidase, and poly (ethylene glycol) diglycidyl ether. Subsequent immobilization of lactate oxidase (LOx) was formed by electropolymerizing the poly (phenylenediamine) film and re-entrapping the enzymatic layer with 
chitosan. The amperometric sensor showed good selectivity against possible interferences, e.g., glucose, uric acid, and ascorbic acid. By using Os-complex mediator, the sensor could operate at a low working potential ( $0 \mathrm{~V}$ versus printed $\mathrm{Ag} / \mathrm{AgCl}$ ), offering reproducible output and long-term applicability. It should be highlighted that the low oxidation potential is advantageous for biosensors, especially for the detection in complex biofluids. Other redox polymers can also be candidates to facilitate the oxidation and reduction in enzymatic electrochemical systems [94]. For instance, the application of ferrocene modified linear polyethylenimine coupled with buckypaper was also demonstrated [95]. The strategy of coupling the redox polymer and carbon nanomaterials displayed effective mediate electron transfer from LOx, showing a low Michaelis-Menten constant and a low oxidation potential. This redox polymer/oxidase-based electrode also used as an anode to couple with a cathode to build a self-powered amperometric biosensor.

A trend in biomedical sensing devices is to achieve self-sustainable sensing devices [96]. This would need a system that contains a continuous and effective energy sources. The initial concept to pave a way in the development of easy-to-wear biosensors was demonstrated by engineering stretchable and textile-based biofuel cells [97]. In addition to harvesting the energy from the wearer, this on-body energy-conversion gadget was designed to provide self-powered analytical signals for monitoring metabolites (i.e., glucose and lactate). Tremendous and continued efforts of researchers aimed to push self-powered systems further. Recently, another interesting example of the new self-powered lactate biosensing system was reported, as shown in Figure 4A [98]. In this device, the key sensitive electrode was realized by using a porous carbon material immobilized with LOx. When using hydrophobic carbon nanotube (CNT)-based materials, hydrophobicity of the electrode surface is an obstacle as the hydrophobic surface would limit the absorption of the perspiration. Annealing the CNT-based electrode at $375^{\circ} \mathrm{C}$ is a strategy to generate favorable hydrophilicity of the porous carbon electrode. The electrode was designed to convert the thermal energy into electricity and also provide an analytical signal. The principle of the biosensing system relied on the evaporation-biosensing coupling effect. Evaporation of solutions from the electrode surface can generate the energy; the generated electrical energy is then stored in the capacitive electrode. This energy can be utilized to power electronics and sensing systems. In the presence of lactate, the enzymatic oxidation of lactate with the assistance of LOx can generate peroxide. This generated product was important to affect the surface. In other words, the increase of the lactate level in the perspiration (causing the increase of peroxide concentration) could change the zeta potential of the porous carbon nanomaterial. This also improved voltage output, giving a useful self-powered analytical signal. This example represents progress in advancing wireless self-sustainable biosensors for modern biomedical applications.

Graphene oxide nanosheets on palladium electrodes were demonstrated to be used in metabolite sensors based on nonfaradaic electrochemical impedance spectroscopy (EIS) as shown in Figure 4B [99]. The electrode and impedometric technique were designed to indicate the impedance shift when resistance and capacitance change. It is essential to fabricate organized structures of nanomaterial-based sheets integrated flexible electrode containing enzymes for the development of biosensors. The graphene oxide nanosheets were distributed into a number of pores of nanoporous polyamide electrode using vacuum over the electrode sensing area. The subsequent functionalization of 1-pyrenebutyric acid-N-hydroxysuccinimide ester as a crosslinker and LOx was accomplished. In the presence of lactate, LOx catalyzes the oxidation of lactate to form $\mathrm{H}_{2} \mathrm{O}_{2}$. The generated $\mathrm{H}_{2} \mathrm{O}_{2}$ can then be oxidized to electrochemically charge ions, giving change in total impedance of the system and EIS signal. Due to the high surface-to-volume ratio of graphene oxide nanosheets and the design of the miniaturized electrode area, only a small volume (lower than $5 \mu \mathrm{L}$ of the testing fluid) was required for the sensing event. The sensor provided a wide dynamic range to detect sweat lactate over a relevant range (1-100 mM lactate). 


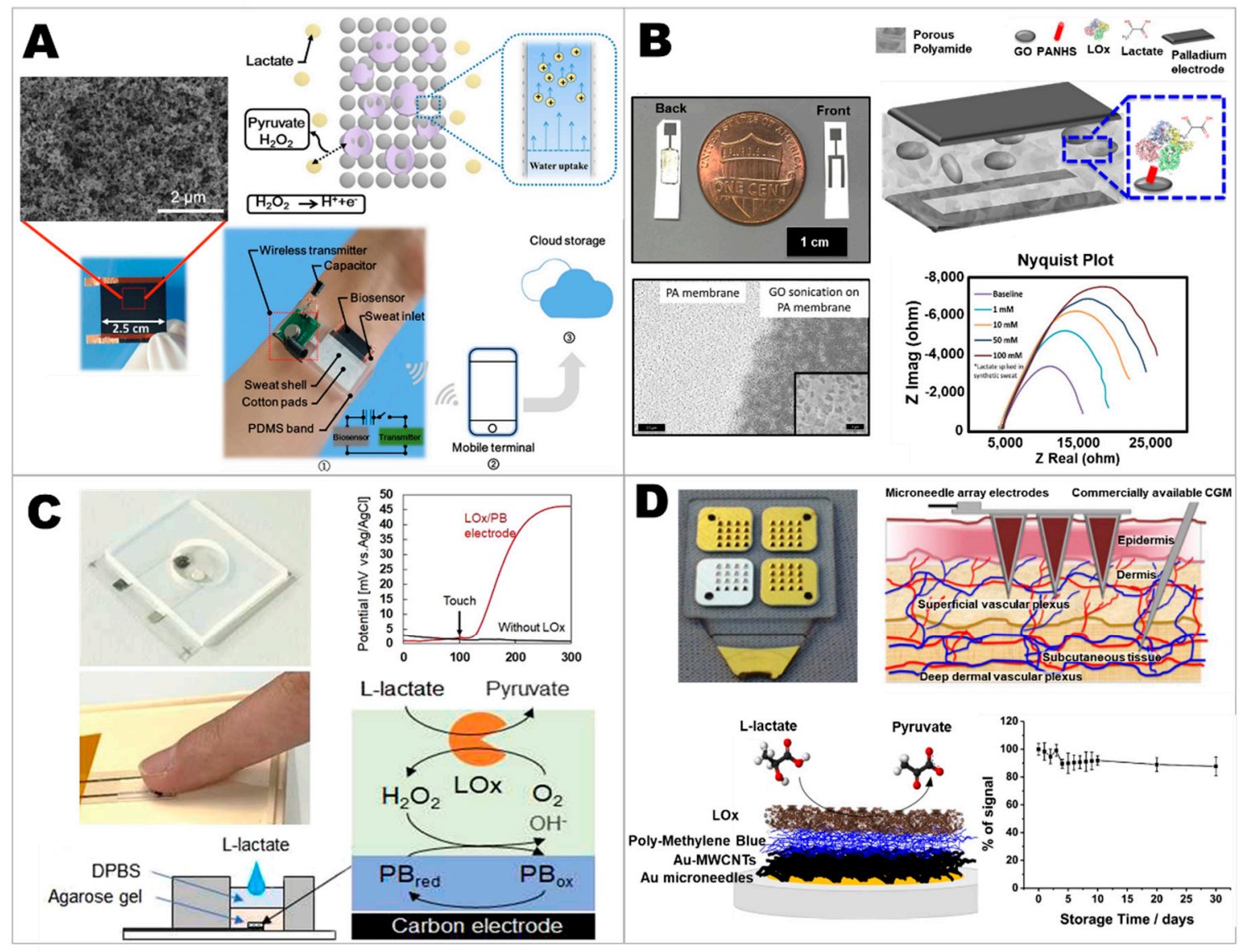

Figure 4. Examples of lactate sensors. (A) Self-powered lactate sensors. Adapted with permission from [98], copyright 2019, Elsevier. (B) Flexible graphene oxide-based lactate sensors. Adapted with permission from [99], copyright 2020, Elsevier. (C) Potentiometric lactate sensors. Adapted under the terms and conditions of the CC-BY 4.0 from [100], copyright 2019, Nagamine et al., published by Sci. Rep. (D) Microneedle-based lactate sensors. Adapted with permission from [101], copyright 2019, Elsevier.

Amperometry is a widely used technique that can be applied for the development of lactate biosensors. For examples, the printed $\mathrm{Ag} / \mathrm{AgCl}$ electrode, printed gold electrode, and the biocatalyst-modified gold electrode could be used as reference, counter and working electrodes, respectively [102]. Carbon nanotubes and chitosan were used to functionalize the enzyme on the working electrode. When developing biosensors used for the detection of untreated biosamples, the mediator is a key to minimize the challenge of oxygen dependence and allow a low detection potential, thus mitigating interfering effects [103]. For example, tetrathiafulvalene could help to decrease the detection voltage to be in a low range of $0-0.2 \mathrm{~V}$ [102].

Not limited to amperometry, an electrochemical transducer can allow for potentiometric biosensing analysis. The PB-based working electrode modified with LOx was integrated with hydrogel-based touch sensor for noninvasive detection of lactate in sweat by potentiometric technique (Figure 4C) [100]. The sensor was fabricated by inkjet-printing the silver nanoparticle ink on the polyethylene naphthalate substrate. Graphite-PB and $\mathrm{Ag} / \mathrm{AgCl}$ inks were coated on the electrode areas of the working and reference electrodes, respectively. Finally, LOx with chitosan entrapment was immobilized on the PB electrode. To prove the concept of the touch-to-detect sensor, the agarose pad prepared in phosphate buffer was placed on the active area of the sensor. Lactate and matrix in sweat were extracted and diffused into the gel. With the assistance of the selective oxidase enzyme, only lactate oxidation can be catalyzed to form $\mathrm{H}_{2} \mathrm{O}_{2} \cdot \mathrm{H}_{2} \mathrm{O}_{2}$ is subsequently oxidized by the PB-based material, causing the analytical signal of potential difference, which could be monitored by reading the open-circuit potential. 
The sensor provided fast response within $20 \mathrm{~s}$ after touching the finger with good sensitivity and reproducibility. However, related challenges may link to skin temperature and the dynamic amount of sweat generated by individual may affect the output.

Another interesting platform is a microneedle-based biosensor. Microneedles allow electrodes to access the analyte under the skin. Microneedle-based electrodes have been demonstrated for minimally invasive detection of a variety of analytes, such as glucose, lactate, uric acid, etc. [104-106]. As shown in Figure 4D, an example of a second-generation-based biosensor was demonstrated in a microneedle platform for lactate detection [101]. Gold microneedles were used as the stable and conductive core. This gold electrode was then coated with Au-MWCNTs, followed by the polymerization of methylene blue. The resulting polymethylene blue was immobilized with LOx. The mediated system allowed a detection potential of $+0.15 \mathrm{~V}$ versus the saturated calomel electrode (SCE). This mediated lactate biosensor could yield a high sensitivity toward the detection of lactate in artificial interstitial fluid, while providing a lower sensitivity when testing the sensor in human serum. This example suggests challenges pertaining to biofouling and passivation. Engineering nanomaterial composites and membranes would be helpful to address such challenges when using electrodes in real complex samples [107-109].

\subsection{Developing Electrolyte Sensors}

Most of the sensors for monitoring electrolyte levels that have been developed rely on the potentiometric technique [110]. As the development of wearable sensors is needed to overcome the challenge pertaining to the mechanical aspects when considering the application with real biological systems, it is essential to make the sensor to be both mechanically compliant and robust [96,111]. This mechanical quality is significant to reserve electrochemical performances during the deformation of the sensor. Engineering materials are, therefore, important to develop the effective wearable sensor. One of strategies is utilizing fiber-based sensor which can be directly woven into textiles. A nanowire is an interesting material to be applied for flexible and stretchable electrodes. An example of AuNWs is for improving the stretchability of traditional rigid solid-state ion-selective electrode (ISE) [88]. The AuNW-based ISE was fabricated by vertically aligning and bonding AuNWs to PDMS elastomers using facile solution-based method and a seed-mediated approach combining photolithography. The electrochemical performance of the sensor was maintained under deformation at $30 \%$ strain. Future efforts may need to consider more ways to improve the signal stability as the device needs to be stabilized by multiple cycles of 500 iterations before use in real monitoring. In addition, the strategy, called a surface strain redistributed elastic fiber, has been recently proposed for sweat sodium sensors as shown in Figure 5A [112]. The active sensing material of the fiber sensor was designed to be a unilateral bead structure by preliminarily dropping Ecoflex prepolymer onto the fiber, allowing the intrinsic stretchability owing to the elastomeric property. The ion-selective electrode and the reference are fabricated by the similar processes: drop-casting the ion-selective membrane solution and $\mathrm{Ag} / \mathrm{AgCl}$ ink onto the bead region, respectively, to form the active layers. This electrode design can redistribute the sensing surface strain even the deformation of $200 \%$ strain, enabling high capability to integrate into the textile-based potentiometric sodium sensor for sweat-detection applications with high stretchability and sensing stability.

Enhancing the sensitivity of the sensor is important. Researchers aim to develop super-Nernstian potentiometric sensing systems to go beyond the theoretical sensitivity. An example of utilizing nanofiber-polymer composites for developing the sensitive potentiometric $\mathrm{pH}$ sensor was reported (Figure 5B) [113]. To improve the surface area of the sensor, the composite solution of tungsten oxide nanofibers and chloromethylated triptycene poly (ether sulfone) polymer was functionalized onto the glassy carbon electrode. The nanofiber structure of the oxide material could be stabilized in the reactive polymer binder. In addition, an amplifier, metal-oxide field-effect transistor (MOSFET), was employed to achieve a sensitive $\mathrm{pH}$ response by integrating differential electronic amplifier. The combined system provided a high sensitivity toward $\mathrm{pH}$ detection $(-377.5 \mathrm{mV} / \mathrm{pH})$, exceeding the theoretical Nernstian behavior (i.e., about $-59 \mathrm{mV} / \mathrm{pH}$ ), offering high precision in detection. Nonetheless, a narrow range of $\mathrm{pH}$ detection (6.90-8.94) is still a challenge. 


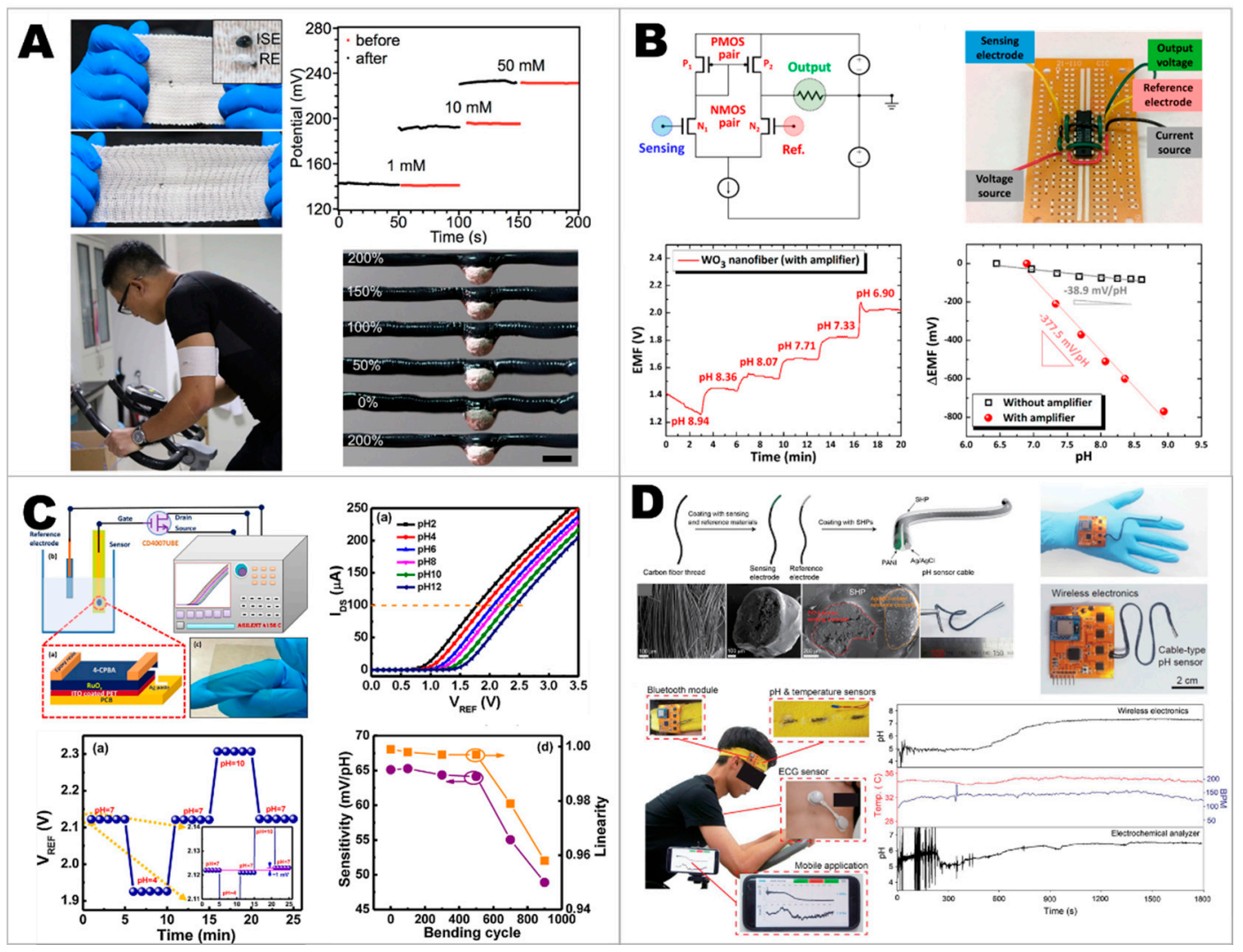

Figure 5. Examples of sensors for electrolyte detection. (A) Strain redistributed fibers for stretchable sodium sensors. Adapted with permission from [112], copyright 2020, Elsevier. (B) $\mathrm{WO}_{3}$ nanofiber-polymer composites for the amplification system of $\mathrm{pH}$ sensors. Adapted with permission from [113], copyright 2019, American Chemical Society. (C) Sol-gel-derived ruthenium oxide on the flexible extended-gate field-effect transistor for super-Nernstian $\mathrm{pH}$ sensors. Adapted with permission from [114], copyright 2019, Elsevier. (D) Self-healable and flexible cable-type pH sensors. Adapted with permission from [115], copyright 2020, Elsevier.

Another type of field-effect transistor (FET) technique, called extended-gate field-effect transistor (EGFET), was also used for super-Nernstian $\mathrm{pH}$ sensor; sol-gel ruthenium oxide ( $\mathrm{RuOx}$ ) as the $\mathrm{pH}$ sensitive sensing membrane was integrated as shown in Figure 5C [114]. Similar to the general FET system, the interaction between the transducer and electrolytes in the sample would cause the electric field on the surface of the sensor, changing the conductivity channel between source and drain. The RuOx-based EGFET sensor was fabricated by spin coating RuOx sol-gel solution onto the surface of an indium tin oxide-coated polyethylene terephthalate (PET) substrate. After drying, the sensing area of the RuOx film was limited with epoxy resin. When the applied current between the source and drain is equal to $100 \mu \mathrm{A}$, the voltage output $\left(\mathrm{V}_{\mathrm{REF}}\right)$ toward the $\mathrm{pH}$ detection displayed the high response of $65.11 \mathrm{mV} / \mathrm{pH}$ over a wide $\mathrm{pH}$ range of 2-12. It should be noted that this highly sensitive $\mathrm{pH}$ sensor can be applied further for the metabolite measurement (e.g., glucose). 4-carboxyphenyl boronic acid could be functionalized onto the RuOx sensing film for glucose detection through the covalent binding, generating the negatively charge of glucose-boronate ester complex and subsequently leading the shift in the potential $\left(\mathrm{V}_{\mathrm{REF}}\right)$ when interacting with glucose. Therefore, non-enzymatic glucose sensors could be obtained.

Apart from flexibility, self-healing ability of materials is interesting to integrate with soft or modern electrochemical sensors $[96,116]$. An example of a wearable potentiometric $\mathrm{pH}$ sensor was proposed in form of cables which can easily be knitted into textile (Figure 5D) [115]. Carbon fiber threads were used as the two-electrode system. The polyaniline-based sensing electrode was prepared by performing the 
electropolymerization of aniline monomer onto the carbon thread surface. The reference electrode was obtained from subsequently coating carbon fiber thread with $\mathrm{Ag} / \mathrm{AgCl}$ ink and by polyvinyl butyral. The obtained electrodes were finally dip-coated with self-healing polymers compose of poly (1,4-cyclohexanedimethanol succinate-co-citrate). The cable sensor was built by weaving the two coated electrodes together. Good linear-Nernstian sensitivity of $58.28 \mathrm{mV} / \mathrm{pH}$ was obtained in a wide $\mathrm{pH}$ range of 3.89-10.09 with excellent repeatability and durability. As the electrodes were coated with the self-healing polymer, the $\mathrm{pH}$ sensor was highly flexible and autonomously healable, enabling promising high precision and accuracy for wearable sensor. More than $97.8 \%$ healing efficiencies from Nernstian responses could be obtained even after completely cutting and self-healing the sensor for four cycles. For the application toward wearable sensors, the sensor cable was knitted into a headband integrated with wireless electronics and successfully applied for continuously and real-time monitoring electrolyte in human sweat.

\subsection{Developing Wearable Integrated Sensors for Multiplex Detection}

Multiplex detection in one integrated device is in the best interest of researchers to provide many vital parameters. An example employs $\mathrm{CO}_{2}$ laser engraving technique to produce a laser-engraved graphene-based electrode on a polyimide film for wearable uric acid and tyrosine chemical sensors, coupled with physical sensors (temperature and respiration rate) [117]. The laser engraving relies on shining a laser beam on the surface of a substrate material. Graphene from the carbon-atom-containing substrate could be directly generated by the carbonization due to the energy of the beam. The laser was also used to construct microfluidic channels on medical adhesive through ablation for sampling and minimizing sweat vaporization and contamination. For the chemical sensing using voltammetry, the sensor showed good sensitivity and selectivity for uric acid and tyrosine against studied interferences (e.g., glucose, urea, dopamine, and ascorbic acid).

A common material to support several biosensors is PB. Nevertheless, as discussed earlier about PB-material-related obstacles, researchers have attempted to address such challenges. One alternative strategy is avoiding the use of PB materials. The development of PB-free or mediator-free biosensors is an interesting direction. The use of $\mathrm{PB}$ can be replaced by developing other electrocatalytic materials to support the fabrication of sensors. A recent example is employing a composite of platinum nanoparticles and MWCNTs (as shown in Figure 6A) [118]. The electrochemical interface was integrated with poly-m-phenylenediamine membrane. This permselective layer was designed to minimize interfering species [119-121]. This is an important factor when developing modern biosensors that will be used directly in complex biological samples. The Pt-based electrocatalyst was coupled with the surface of MWCNTs to enhance the electrocatalytic properties to support peroxide-based sensing mechanisms. Such an electrochemical transducer could be immobilized with corresponding oxidase enzymes (including GOx, LOx, and choline oxidase) to form glucose, lactate, and choline biosensors, respectively. The resulting mediator-free sensors could cover detection ranges of $0-300 \mu \mathrm{M}$ glucose; $0-20 \mathrm{mM}$ lactate; and $0-300 \mu \mathrm{M}$ choline. The developed biosensors were also coupled with miniaturized electronics and smartwatch to allow the demonstration of biosensors to monitor biomarkers contained in sweat. This example represents another progress toward the development of modern sensors for personal healthcare management.

Another important challenge in electroanalytical chemistry, particularly for the potentiometric method, pertains to the potential instability of the electrode. Engineering the surface material used to develop sensors is a primary consideration. It is essential that the interfacial property on the electrode transducer should be tuned carefully. An example of an approach to fabricate wearable ion sensors was demonstrated, as shown in Figure 6B [122]. A fluorinated alkyl silane $\left(\mathrm{CF}_{3}\left(\mathrm{CF}_{2}\right)_{7} \mathrm{CH}_{2} \mathrm{CH}_{2} \mathrm{SiCl}_{3}\right)$ was used to enhance the hydrophobicity of the paper-based electrode surface. The surface coating was carried out by using vaporized fluorinated alkyl silane (in a vacuum drying chamber at $80^{\circ} \mathrm{C}$ ). This step is important as it is necessary to form a homogenously coated film. In addition, the coating could help to minimize the problem of the water-layer effect. The resulting hydrophobic paper was 
then spray-coated by using a graphene dispersion, creating a good conductive nanomaterial-based surface. This coating was designed to ensure the quality of the ion-to-electron transducer in the electrode sensor. Afterward, the electrode was then functionalized by ionophore-based membranes (such as potassium-, sodium-, $\mathrm{pH}-$, and chloride-selective membranes). For example, the $\mathrm{K}^{+}$-selective membrane relied on valinomycin, while the membrane for the reference electrode relied on potassium tetrakis (4-chlorophenyl) borate, tridodecylmethylammonium chloride, bis(2-ethylhexyl)sebacate, and polyvinyl chloride. This design could offer all-solid-state ion-selective electrodes with stable and fast response performances. Moreover, this approach utilizing a paper substrate represents an interesting example to build a flexible sensor.

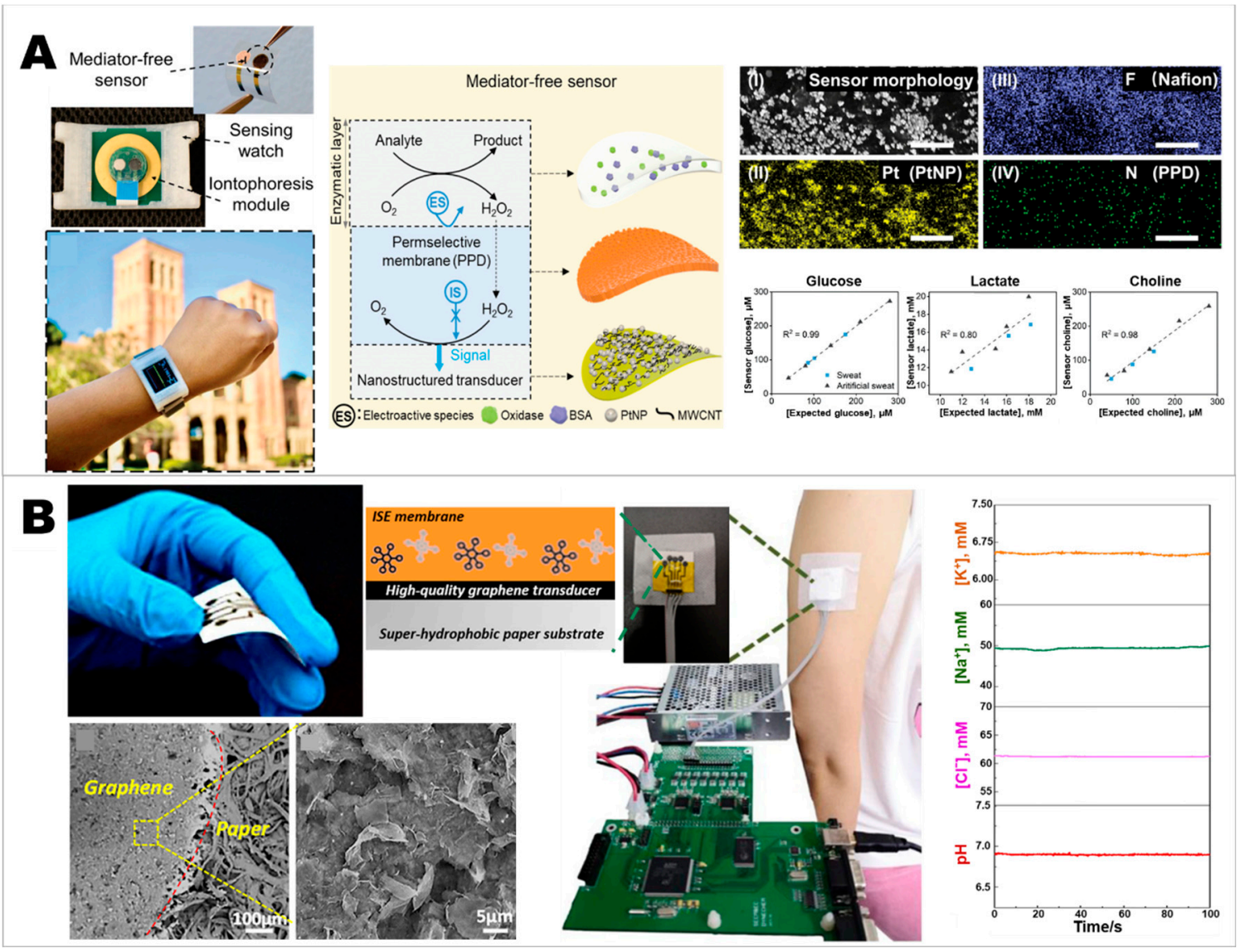

Figure 6. Examples of wearable sensors for monitoring multianalytes. (A) Mediator-free enzymatic sensors for the development of wearable glucose, lactate, and choline biosensors. Adapted with permission from [118], copyright 2019, Wiley-VCH. (B) The application of graphene-based materials to develop all-solid-state wearable potentiometric sensor for various ion monitoring. Adapted with permission from [122], copyright 2019, Elsevier.

Moreover, the combination of chemical sensors (including non-electrochemical techniques) with physical sensors would allow opportunities to realize a single wearable device with versatile utilities. For example, graphene oxide combined inverse opal acetylcellulose (IOAC) film was utilized to develop flexible sensor for simultaneous monitoring of human motion and salt concentration in sweat [123]. Graphene oxide served as motion sensor as the material was designed to display a resistance change when applying mechanical movement, while the IOAC film served as a flexible substrate and a sweat ion indicator via the change of color when adsorbing ions. In addition to developing a device that can only detect sweat, an integrated sensor that can expand to detect other vital signs (e.g., temperature) together with the perspiration sensing function would be of great interest. For example, textile sensor integrated wireless communication system have been developed for real-time body temperature and 
sweat sensing [124]. Conductive threads which can be integrated with conventional textiles used in daily life was utilized to implement antennas, offering a wearable capacitive circuit for wireless power supply and communication systems. This example of hybrid sensors, combining physical sensors and chemical sensors, not only allowed tracking real-time wellbeing but also sharing data remotely, is important to improve personal diagnosis and treatment efficiency.

\section{Moving toward Modern Electrochemical Detection of Viruses}

Viruses are an example of pathogenic threats to human health worldwide $[125,126]$. A current and critical example is the coronaviruses, which is causing severe pandemic problems globally. Recently, the novel coronavirus 2019 (COVID-19) has become a serious pathogen and the World Health Organization (WHO) has declared a global health emergency [127-130]. In addition to therapeutic and preventive efforts, efficacious diagnostic tools are crucial. This has stimulated researchers to explore modern diagnostic analysis for fast and specific detection of the virus. In addition to such an emerging pathogen, a number of deaths worldwide have been reported due to influenza virus [131,132]. Influenza A is one of the most prevalent infectious diseases which can lead to the seasonal flu and future health complications. It is also possible to be infectious. Therefore, it is important to warn of the outbreak of the virus by using a fast and convenient platform that users can easily access. Hence, methods for rapid diagnosis with features of high selectivity, sensitivity, accuracy, convenience, and portability are needed. The new effective analytical tools would allow early antiviral management and treatment, limiting the spread of infectious viruses as quickly as possible. Electrochemical detection is one of attractive methods for such purposes. Importantly, electrochemical biosensors represent promising tools for selective diagnosis. For example, DNA-aptamer-based biosensors have great potential to differentiate the virus subtypes [133]. This quality is a crucial parameter of analytical methods, particularly for reliable biomedical diagnosis and clinical need. In order to realize on-site and compact devices, electrochemical approaches become an attractive candidate as they hold the potential to achieve high sensitivity and rapid detection while requiring small samples. A common biosensor contains two main units: a biorecognition (receptor) unit that interacts with its analyte and a transducer. Nanomaterials can also help to enhance the quality of immobilization and improve desirable analytical qualities, such as sensitivity [134,135]. Some recent examples will be discussed in this section.

An example of the new strategy is to integrate electrochemical sensors for virus detection with textile or conventional substrates. For example, fabrics or flexible substrates are attractive to develop modern virus-detection sensors. A recent example using graphene oxide- and textile-based impedometric sensors was demonstrated, as shown in Figure 7A [136]. This example employed the electrochemical impedance spectroscopy (EIS) method to measure the impedance shift when the resistance and capacitance change. This example sensor was built by screen-printing conductive silver ink as a base electrode on textiles or substrates to form a two-electrode system. The subsequent layer of graphene oxide was coated as the transduction layer on silver traces. For targeting influenza detection, pyrenebutyric acid-N-hydrosuccinimide ester was used as a crosslinker to conjugate the influenza antibody on the layer of the carbon nanomaterial. Note that the oxide form of the graphene material, possessing oxygen rich-containing moieties, is essential to conjugate with biomolecules for developing the biorecognition layer (e.g., to recognize the influenza target). Moreover, electron transport enhanced by nanomaterials at the electrode-solution interface is also advantageous for the EIS detection. After the incubation of the influenza sample on the sensor for less than $10 \mathrm{~min}$, the EIS could be recorded. The measured impedance shifts of the sensor showed linear relationship to the influenza protein concentration in the range of $10 \mathrm{ng} \mathrm{mL}^{-1}$ to $10 \mu \mathrm{g} \mathrm{mL}^{-1}$. This detection range is compatible with the average expression of the virus in a patient $\left(\sim 50 \mathrm{ng} \mathrm{mL}{ }^{-1}\right)$, indicating potential use of the personalized or miniaturized sensors to quickly screen for the virus. Nonetheless, studies were performed in a laboratory setting. Therefore, the practical application in real virus exposure must be studied and optimized, including the effect of environmental conditions, interference studies, and the integration with electronics and big data systems. 


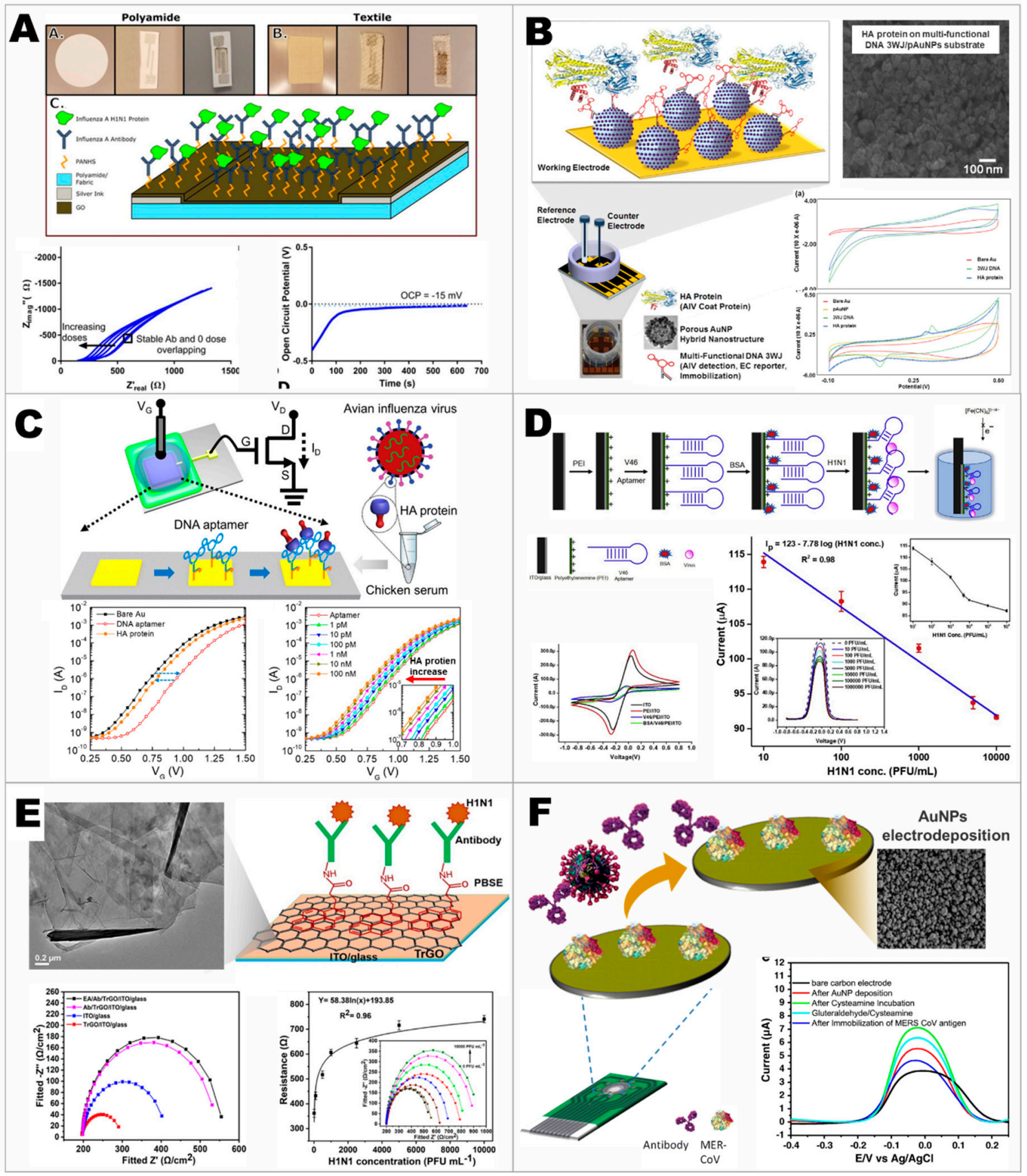

Figure 7. Examples of electrochemical sensors that have the potential for the development of point-of-care virus detection. (A) Wearable electrochemical biosensor for the detection of influenza virus. Adapted under the terms and conditions of the CC-BY 4.0 from [136], copyright 2018, Kinnamon et al., published by J. Electrochem. Soc. (B) Electrochemical biosensors for the detection of avian influenza virus (H5N1). Adapted with permission from [137], copyright 2019, Elsevier. (C) Aptamer-based field-effect transistor for the detection of avian influenza virus. Adapted with permission from [138], copyright 2020, American Chemical Society. (D) Label-free electrochemical biosensors for the detection of the subtyping of Influenza A H1N1 virus. Adapted with permission from [133], copyright 2019, Elsevier. (E) Reduced graphene oxide-based biosensors for the detection of influenza virus. Adapted with permission from [139], copyright 2020, Elsevier. (F) Electrochemical array biosensors for the detection of the Middle East respiratory syndrome coronavirus (MERS-CoV) and human coronavirus (HCoV). Adapted with permission from [140], copyright 2019, Springer Nature. 
Avian influenza virus (AIV), such as the H5N1 virus, is an example that can also transmit from birds to human [141,142]. In general, labelling processes, involving the labeling of enzymes and fluorescent or radioactive substances to the target, are required as many biological analytes has limitations of their intrinsic physical properties, causing difficulty of direct detection. Therefore, it is preferable to avoid the additional labeling approach when moving forward to handy devices. Sensors based on the label-free technique offers a potential to integrate into lab-on-a-chip devices for real-time biodetection. Recent example of the development in electrochemical sensors is the biosensors utilizing multifunctional three-way-junction DNA structure and porous Au nanoparticles on Au electrodes, as shown in Figure 7B [137]. The hemagglutinin protein is an important marker component of the virus surface glycoproteins. Therefore, the DNA biomaterial was designed to give an arm for additional functionalization, allowing the attachment of hemagglutinin-protein aptamer for AIV detection unit. This was also important to link with a redox reporter or thiol bonding. The 'horseradish-peroxidase-mimicked' DNAzyme with the hemin was also used. It should be highlighted that a combination of DNA and hemin complex is a promising candidate to serve as an effective and robust bioelectrocatalyst, compared with traditional protein-based enzymes [143]. In addition, it is necessary to achieve a low limit of detection for measuring the concentration of hemagglutinin protein. Therefore, porous Au nanoparticles were also modified on the Au surface as an electrode base. The high porosity of the nanomaterial-based surface, providing a high effective surface area, offered the favorable functionalization of biomolecules [144-146]. This biosensor represents a strategy to simplify diagnostic processes, eliminating amplification and labeling steps.

Another example application of aptamer-based sensors is targeting hemagglutinin protein for the detection of H5N1 AIV (Figure 7C) [138]. This example relied on a microelectronic interface, the field-effect transistor (FET). The DNA three-way-junction aptamer specific to biomarkers of AIV was directly modified on the surface of the planar gold electrode without the need of thiol linkers to use as the sensing electrode. The modified electrode was then connected to the gate of FET transducer. For detection, the AIV contained in the sample would bind to the sensing aptamer, leading to a change of the electric field generated in the FET system and subsequently change the drain current output. In this case, the signal increased with increasing AIV concentration. The sensor provided high sensitivity to detect AIV at the picomolar level without the requirement of molecular amplification and was successfully applied to chicken serum samples. The aptamer-based sensor also offered high stability when compared with an antibody-based sensor, giving field-use advantage.

Additionally, an example is the sensor based on DNA aptamer modification for the detection of the H1N1 subtype of avian influenza virus (AIV) (Figure 7D) [133]. An indium tin oxide-coated glass electrode was used and modified with (3-aminopropyl) trimethoxysilane to serve as a linker for further immobilizing the DNA aptamer. The aptamer recognition layer was specific to the hemagglutinin protein, which is a biomarker of AIV. This binding assay decreased the voltammetric signal of the electrode in the redox probe solution. This electrochemical sensor offered high sensitivity for detection of the H1N1 subtypes in the nanomolar range. However, the DNA aptamer amplification technique, systematic evolution of ligands by exponential enrichment, was still needed prior the electrochemical assay.

Another example that applies nanomaterials for pathogen analysis is using graphene-based electrodes for the fabrication of virus sensors, as shown in Figure 7E [139]. Shellac biopolymer could be converted into conductive graphene by using a 'green' approach. Shellac flakes were heated in a vacuum chamber. The high temperature $\left(700^{\circ} \mathrm{C}\right)$ could carbonize the flakes after 15 min, yielding graphene. This synthesis approach to prepare nanocarbon materials was effective and yielded a carbon content around $97 \%$. The resulting thermally decomposed reduced graphene oxide displayed a high electrical conductivity. Therefore, this carbon nanomaterial could be used as a stable electrode for the subsequent bioimmobilization. The linker (i.e., 1-pyrenebutanoic acid succinimidyl ester) was functionalized on the carbon surface to provide noncovalent interactions via $\pi-\pi$ stacking and bioconjugation bonding with the amine in H1N1 antibodies (for the influenza A virus subtype H1N1), serving as the selective biorecognition layer. The analytical calibration curves for the detection of the virus could be obtained by measuring the change in electrochemical impedance spectra. The higher the amount of virus, the greater 
the bound sites. Hence, the signal was obtained by the measurement of charge transfer resistance values. The charge transfer resistance increased significantly upon increasing the virus concentration levels, until it reached a relatively steady value. The obtained limits of detection studied in buffer and saliva yielded 26 and 33 plaque-forming units (PFU, referring to the amount of virus) $\mathrm{mL}^{-1}$, respectively. This approach represents another example that used cost-effective nanomaterials to fabricate pathogen electrochemical sensors.

Even though researchers still keep putting their efforts on developing new biosensors for coronavirus, principles that have been reported are helpful to the research progress. The Middle East respiratory syndrome coronavirus (MERS-CoV) is another serious pathogen, causing viral respiratory sickness [147]. An example of biosensors is developing competitive electrochemical immunosensing systems for the multianalyte detection of coronaviruses, e.g., MERS-CoV and human coronavirus $(\mathrm{HCoV})$, as shown in Figure 7F [140]. The electrode relied on a nanomaterial-modified carbon electrode. Gold nanoparticles were electrodeposited to modify the carbon array electrode to ensure the good conductivity of the electrode and maximize the effective surface area for the immobilization of antibodies. The principle of this limited amount of antibody assay was based on the indirect competition between the immobilized MERS-CoV protein and the pathogenic analyte available in the patient's fluid (unknown virus amount). The binding of the antibody deposited on the electrode surface, insulating the electrode surface, caused the decrease of the electrochemical current of the electrode in $\mathrm{Fe}(\mathrm{CN})_{6}{ }^{3-/ 4-}$ solution. The current signal obtained from the voltammogram was inversely proportional to the concentration of the virus target. This assay with array electrodes, which takes $20 \mathrm{~min}$ and opens a possibility to functionalize various specific antigens for multianalyte electrochemical analysis on one chip.

The development of modern diagnostic system is essential to control the pathogenic spread, such as the COVID-19 pandemic. Easy-to-access platforms, such as smartphone-based sensing devices, would empower people to connect with healthcare services (Figure 8). The out-of-clinic sensor should be simple and allow the integrative diagnostic system to connect with digital health. Applying functional nanomaterials can yield extraordinary functionalities in the selective and sensitive electrochemical devices. The electrochemical sensor is ready to provide an electrical signal, allowing the convenience to the development of digital integrated systems. In addition, the public health organization could obtain the clear and real-time epidemiological data, analyze the data, and share the information. This strategy would help to support personal healthcare management and policy regulation.

Ultimately, researchers aim to develop a sensitive way to directly diagnose the original genetic target, compared with depending on amplified nucleic acids. For example, an immunosensor for fast and high sensitivity detection of a virus (e.g., Fig mosaic virus) was developed, relying on the antigen-antibody recognition [148]. The gold electrode surface was modified with the self-assembly monolayer of 11-mercaptoundecanoic acid and 3-mercapto propionic acid before immobilizing the biorecognition layer via the drop-casting method. As the self-assembly monolayer formed with long chain alkanethiol, redox reaction between solution and electrode could be achieved. The voltammetric mode was utilized to measure electrochemical responses before and after having the virus in redox probe solution. In the presence of the virus, the antigen-antibody interaction formed the insulating layer, which hinders the electrochemical reaction on the biosensor surface, leading to a small current output. The developed sensor exhibited high selectivity and sensitivity for the virus detection without the need of the molecular amplification step.

In many cases, the concept of the polymerase chain reaction is also useful to amplify the numbers of copies of specific genetic samples, such as RNA samples from Influenza [149,150]. Moreover, a point-of-care device with a self-powered system is a promising innovation to provide the potential in personalized diagnostic devices. An example is to develop a microfluidic chip using body heat for the process of recombinase polymerase amplification [151]. A flexible chip with microchannels was made of PDMS, enabling conformal skin contact and good heat transfer. The wearable gadget with the function of recombinase polymerase amplification could be used as a wristband. By using this wearable platform, the DNA amplification could be achieved within a half hour. This example could open up the potential for supporting the integrated system for the infectious pathogen detection. 

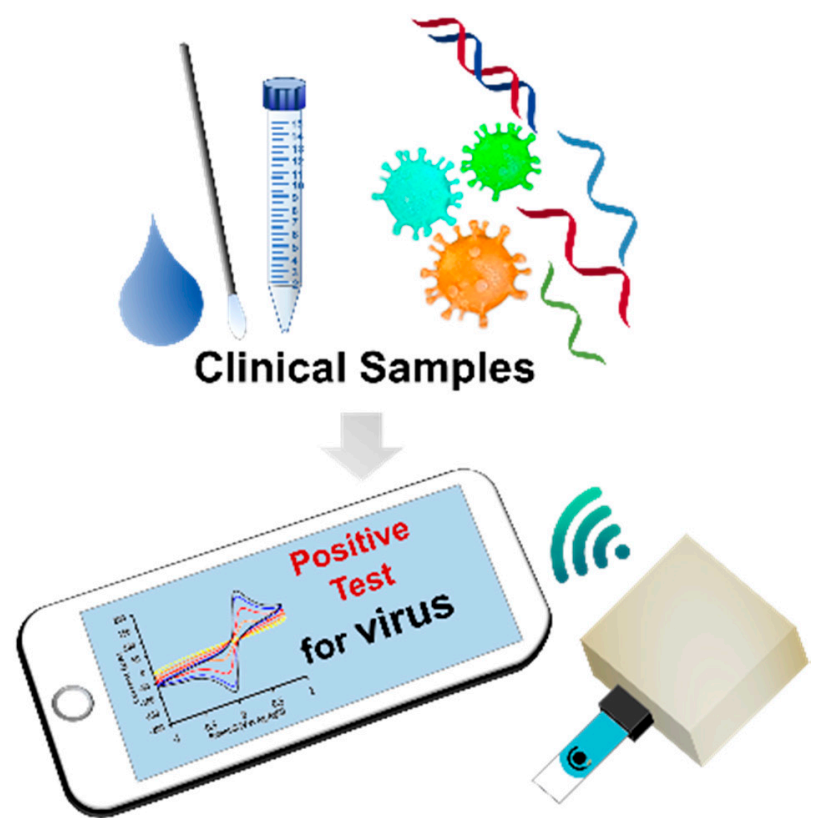

Biomedical Sensors/ Smartphone-Based Units
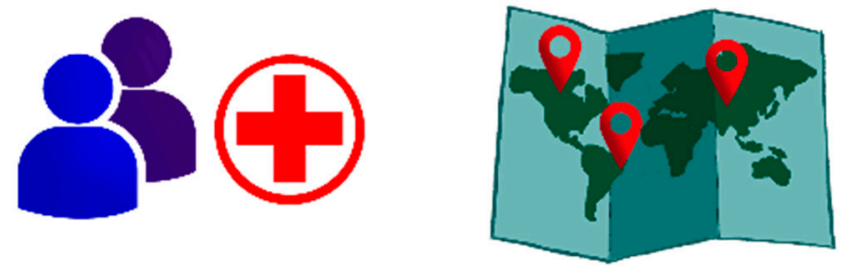

Database

Data Analysis/Report/Management

Figure 8. Schematic illustration showing that the out-of-clinic electrochemical sensor can allow convenient biomedical diagnosis. The data can be sent out to the integrated network, connecting the individual, the local healthcare unit, and the national or international public health organization.

\section{Conclusions and Outlooks}

Nanomaterials have been utilized and demonstrated in wearable, portable, and miniaturized electrochemical sensors for many applications, ranging from quick diagnostic tools to modern healthcare and biomedical applications [17-20]. These open up exciting opportunities to realize immediate or continuous analytical detection of significant biomarkers or pathogens for out-of-clinic biomedical evaluation. Over the last few years, significant advancements have been made, which are highlighted in this article. The related challenges and primary factors that should be considered are also discussed.

We envisage that exploring new nanomaterials and composites would open the door to future development of sensors with outstanding analytical performances. Moreover, the integration with various new concepts should be considered. For instance, the continual development of functional materials to support self-powered sensors could be a crucial paradigm shift in the modern sensing field [152-154]. The integration of electrochemical devices with other techniques would also help to fulfill these requirements. For example, a patch consisting of flexible microfluidic and polymerase amplification systems could be combined with a sensor for the speedy analysis of nucleic acids [155]. Within $10 \mathrm{~min}$, this example of integrated polymerase amplification sensor offered the possibility to 
determine of virus. The combination of spectrophotometric techniques is also attractive [156]. This may expand to the combination of miniaturized fluorescent fiber-based sensors or paper-based colorimetric sensors on wearable or miniaturized platforms [157].

It should be noted that more comprehensive studies await the discovery of deep knowledge about the correlation and meaning of new data obtained from biofluids other than the traditional information obtained from human blood. The research on complex physiological systems and biological mechanisms would be an interesting topic. Different contents of biofluid compositions or co-existing interferences can affect sensor performance. There are several analytical parameters that must also be considered, including selectivity, specificity, precision, accuracy, linearity range, matrix variations, and limit of detection.

We expect that the next development phase of wearable and portable electrochemical sensors for modern out-of-clinic analytical chemistry would provide unprecedented capabilities and convenience to support new lifestyles of users. They would represent the beneficial strategy to warn of health issues in a timely manner and closely track temporal biochemical levels in a convenient manner for a new era of healthcare and biomedical applications.

Author Contributions: I.J. and T.S.-a. contributed equally to this work. I.J. and T.S.-a.; writing-original draft preparation, I.J. and T.S.-a.; writing—review and editing, I.J., T.S.-a., and D.N.; principle Investigation, I.J. All authors have read and agreed to the published version of the manuscript.

Funding: This research received no external funding.

Acknowledgments: T.S.-a. would like to acknowledge the Royal Golden Jubilee program of the Thailand Research Fund: PHD/0140/2558.

Conflicts of Interest: The authors declare no conflict of interest.

\section{References}

1. Qazi, S.; Raza, K. Chapter 4-Smart biosensors for an efficient point of care (PoC) health management. In Smart Biosensors in Medical Care; Chaki, J., Dey, N., De, D., Eds.; Elsevier: London, UK, 2020; pp. 65-85. [CrossRef]

2. Pateraki, M.; Fysarakis, K.; Sakkalis, V.; Spanoudakis, G.; Varlamis, I.; Maniadakis, M.; Lourakis, M.; Ioannidis, S.; Cummins, N.; Schuller, B.; et al. Chapter 2-Biosensors and Internet of Things in smart healthcare applications: Challenges and opportunities. In Wearable and Implantable Medical Devices; Dey, N., Ashour, A.S., James Fong, S., Bhatt, C., Eds.; Elsevier: London, UK, 2020; Volume 7, pp. 25-53.

3. Rath, M.; Pattanayak, B. Technological improvement in modern health care applications using Internet of Things (IoT) and proposal of novel health care approach. Int. J. Hum. Rights Healthc. 2019, 12, 148-162. [CrossRef]

4. Yager, P.; Domingo, G.J.; Gerdes, J. Point-of-Care Diagnostics for Global Health. Annu. Rev. Biomed. Eng. 2008, 10, 107-144. [CrossRef] [PubMed]

5. Lapinski, M.; Brum Medeiros, C.; Moxley Scarborough, D.; Berkson, E.; Gill, T.J.; Kepple, T.; Paradiso, J.A. A Wide-Range, Wireless Wearable Inertial Motion Sensing System for Capturing Fast Athletic Biomechanics in Overhead Pitching. Sensors 2019, 19, 3637. [CrossRef]

6. Vera Anaya, D.; He, T.; Lee, C.; Yuce, M.R. Self-powered eye motion sensor based on triboelectric interaction and near-field electrostatic induction for wearable assistive technologies. Nano Energy 2020, 72, 104675. [CrossRef]

7. Chen, S.; Wu, N.; Lin, S.; Duan, J.; Xu, Z.; Pan, Y.; Zhang, H.; Xu, Z.; Huang, L.; Hu, B.; et al. Hierarchical elastomer tuned self-powered pressure sensor for wearable multifunctional cardiovascular electronics. Nano Energy 2020, 70, 104460. [CrossRef]

8. Kim, J.; Chou, E.-F.; Le, J.; Wong, S.; Chu, M.; Khine, M. Soft Wearable Pressure Sensors for Beat-to-Beat Blood Pressure Monitoring. Adv. Healthc. Mater. 2019, 8, 1900109. [CrossRef] [PubMed]

9. Lee, H.; Chung, H.; Ko, H.; Lee, J. Wearable Multichannel Photoplethysmography Framework for Heart Rate Monitoring During Intensive Exercise. IEEE Sens. J. 2018, 18, 2983-2993. [CrossRef]

10. Jang, D.; Cho, S. A $43.4 \mu \mathrm{W}$ photoplethysmogram-based heart-rate sensor using heart-beat-locked loop. In Proceedings of the 2018 IEEE International Solid-State Circuits Conference-(ISSCC), San Francisco, CA, USA, 11-15 February 2018; pp. 474-476. 
11. Shin, J.; Jeong, B.; Kim, J.; Nam, V.B.; Yoon, Y.; Jung, J.; Hong, S.; Lee, H.; Eom, H.; Yeo, J.; et al. Sensitive Wearable Temperature Sensor with Seamless Monolithic Integration. Adv. Mater. 2020, 32, 1905527. [CrossRef]

12. Trung, T.Q.; Le, H.S.; Dang, T.M.L.; Ju, S.; Park, S.Y.; Lee, N.-E. Freestanding, Fiber-Based, Wearable Temperature Sensor with Tunable Thermal Index for Healthcare Monitoring. Adv. Healthc. Mater. 2018, 7, 1800074. [CrossRef]

13. Al-Halhouli, A.a.; Al-Ghussain, L.; El Bouri, S.; Liu, H.; Zheng, D. Fabrication and Evaluation of a Novel Non-Invasive Stretchable and Wearable Respiratory Rate Sensor Based on Silver Nanoparticles Using Inkjet Printing Technology. Polymers 2019, 11, 1518. [CrossRef] [PubMed]

14. Yamamoto, A.; Nakamoto, H.; Bessho, Y.; Watanabe, Y.; Oki, Y.; Ono, K.; Fujimoto, Y.; Terada, T.; Ishikawa, A. Monitoring respiratory rates with a wearable system using a stretchable strain sensor during moderate exercise. Med. Biol. Eng. Comput. 2019, 57, 2741-2756. [CrossRef] [PubMed]

15. Wang, B.; Wilhelm, A.; Wilhelm, A.; Pilehvar, S.; Moshfeghi, S.; Stout, P.; Salahi, K.; Emaminejad, S. Chapter 2-Wearable chemical sensors. In Wearable Bioelectronics; Parlak, O., Salleo, A., Turner, A., Eds.; Elsevier: Amsterdam, The Netherlands, 2020; pp. 49-63. [CrossRef]

16. Seshadri, D.R.; Li, R.T.; Voos, J.E.; Rowbottom, J.R.; Alfes, C.M.; Zorman, C.A.; Drummond, C.K. Wearable sensors for monitoring the physiological and biochemical profile of the athlete. NPJ Digit. Med. 2019, 2, 72. [CrossRef] [PubMed]

17. Liu, H.; Zhao, C. Wearable electrochemical sensors for noninvasive monitoring of health-A perspective. Curr. Opin. Electrochem. 2020, 23, 42-46. [CrossRef]

18. Ferreira, P.C.; Ataíde, V.N.; Silva Chagas, C.L.; Angnes, L.; Tomazelli Coltro, W.K.; Longo Cesar Paixão, T.R.; Reis de Araujo, W. Wearable electrochemical sensors for forensic and clinical applications. TracTrends Anal. Chem. 2019, 119, 115622. [CrossRef]

19. Bandodkar, A.J.; Jeang, W.J.; Ghaffari, R.; Rogers, J.A. Wearable Sensors for Biochemical Sweat Analysis. Annu. Rev. Anal. Chem. 2019, 12,1-22. [CrossRef] [PubMed]

20. Sempionatto, J.R.; Jeerapan, I.; Krishnan, S.; Wang, J. Wearable Chemical Sensors: Emerging Systems for On-Body Analytical Chemistry. Anal. Chem. 2020, 92, 378-396. [CrossRef]

21. Liu, J.; Geng, Z.; Fan, Z.; Liu, J.; Chen, H. Point-of-care testing based on smartphone: The current state-of-the-art (2017-2018). Biosens. Bioelectron. 2019, 132, 17-37. [CrossRef]

22. Dutta, S. Point of care sensing and biosensing using ambient light sensor of smartphone: Critical review. TracTrends Anal. Chem. 2019, 110, 393-400. [CrossRef]

23. Sun, A.C.; Hall, D.A. Point-of-Care Smartphone-based Electrochemical Biosensing. Electroanalysis 2019, 31, 2-16. [CrossRef]

24. Cappon, G.; Vettoretti, M.; Sparacino, G.; Facchinetti, A. Continuous Glucose Monitoring Sensors for Diabetes Management: A Review of Technologies and Applications. Diabetes Metab. J. 2019, 43, 383-397. [CrossRef]

25. Lisi, F.; Peterson, J.R.; Gooding, J.J. The application of personal glucose meters as universal point-of-care diagnostic tools. Biosens. Bioelectron. 2020, 148, 111835. [CrossRef] [PubMed]

26. O'Malley, E.G.; Reynolds, C.M.E.; O'Kelly, R.; Killalea, A.; Sheehan, S.R.; Turner, M.J. A Prospective Evaluation of Point-of-Care Measurements of Maternal Glucose for the Diagnosis of Gestational Diabetes Mellitus. Clin. Chem. 2020, 66, 316-323. [CrossRef]

27. Chen, H.; Liu, K.; Li, Z.; Wang, P. Point of care testing for infectious diseases. Clin. Chim. Acta 2019, 493, 138-147. [CrossRef] [PubMed]

28. Sri, S.; Dhand, C.; Rathee, J.; Ramakrishna, S.; Solanki, P.R. Microfluidic Based Biosensors as Point of Care Devices for Infectious Diseases Management. Sens. Lett. 2019, 17, 4-16. [CrossRef]

29. Zhang, N.; Wang, L.; Deng, X.; Liang, R.; Su, M.; He, C.; Hu, L.; Su, Y.; Ren, J.; Yu, F.; et al. Recent advances in the detection of respiratory virus infection in humans. J. Med. Virol. 2020, 92, 408-417. [CrossRef] [PubMed]

30. Kim, H.; Chung, D.-R.; Kang, M. A new point-of-care test for the diagnosis of infectious diseases based on multiplex lateral flow immunoassays. Analyst 2019, 144, 2460-2466. [CrossRef]

31. Corman, V.M.; Landt, O.; Kaiser, M.; Molenkamp, R.; Meijer, A.; Chu, D.K.; Bleicker, T.; Brünink, S.; Schneider, J.; Schmidt, M.L.; et al. Detection of 2019 novel coronavirus (2019-nCoV) by real-time RT-PCR. Eurosurveillance 2020, 25, 2000045. [CrossRef]

32. Chu, D.K.W.; Pan, Y.; Cheng, S.M.S.; Hui, K.P.Y.; Krishnan, P.; Liu, Y.; Ng, D.Y.M.; Wan, C.K.C.; Yang, P.; Wang, Q.; et al. Molecular Diagnosis of a Novel Coronavirus (2019-nCoV) Causing an Outbreak of Pneumonia. Clin. Chem. 2020, 66, 549-555. [CrossRef] 
33. Kalambate, P.K.; Dhanjai; Huang, Z.; Li, Y.; Shen, Y.; Xie, M.; Huang, Y.; Srivastava, A.K. Core@shell nanomaterials based sensing devices: A review. TracTrends Anal. Chem. 2019, 115, 147-161. [CrossRef]

34. García-Carmona, L.; González, M.C.; Escarpa, A. Nanomaterial-based electrochemical (bio)-sensing: One step ahead in diagnostic and monitoring of metabolic rare diseases. TracTrends Anal. Chem. 2019, 118, $29-42$. [CrossRef]

35. Xiao, T.; Huang, J.; Wang, D.; Meng, T.; Yang, X. Au and Au-Based nanomaterials: Synthesis and recent progress in electrochemical sensor applications. Talanta 2020, 206, 120210. [CrossRef] [PubMed]

36. Valentini, F.; Palleschi, G. Nanomaterials and Analytical Chemistry. Anal. Lett. 2008, 41, 479-520. [CrossRef]

37. Adeel, M.; Bilal, M.; Rasheed, T.; Sharma, A.; Iqbal, H.M.N. Graphene and graphene oxide: Functionalization and nano-bio-catalytic system for enzyme immobilization and biotechnological perspective. Int. J. Biol. Macromol. 2018, 120, 1430-1440. [CrossRef] [PubMed]

38. Cipolatti, E.P.; Valério, A.; Henriques, R.O.; Moritz, D.E.; Ninow, J.L.; Freire, D.M.G.; Manoel, E.A.; Fernandez-Lafuente, R.; de Oliveira, D. Nanomaterials for biocatalyst immobilization-State of the art and future trends. RSC Adv. 2016, 6, 104675-104692. [CrossRef]

39. Bilal, M.; Iqbal, H.M.N. Chemical, physical, and biological coordination: An interplay between materials and enzymes as potential platforms for immobilization. Coord. Chem. Rev. 2019, 388, 1-23. [CrossRef]

40. Sassolas, A.; Blum, L.J.; Leca-Bouvier, B.D. Immobilization strategies to develop enzymatic biosensors. Biotechnol. Adv. 2012, 30, 489-511. [CrossRef]

41. Zhang, Y.; Huang, B.; Yu, F.; Yuan, Q.; Gu, M.; Ji, J.; Zhang, Y.; Li, Y. 3D nitrogen-doped graphite foam@Prussian blue: An electrochemical sensing platform for highly sensitive determination of $\mathrm{H}_{2} \mathrm{O}_{2}$ and glucose. Microchim. Acta 2018, 185, 86. [CrossRef]

42. Komkova, M.A.; Zarochintsev, A.A.; Karyakina, E.E.; Karyakin, A.A. Electrochemical and sensing properties of Prussian Blue based nanozymes "artificial peroxidase". J. Electroanal. Chem. 2020, 114048. [CrossRef]

43. Komkova, M.A.; Pasquarelli, A.; Andreev, E.A.; Galushin, A.A.; Karyakin, A.A. Prussian Blue modified boron-doped diamond interfaces for advanced $\mathrm{H}_{2} \mathrm{O}_{2}$ electrochemical sensors. Electrochim. Acta 2020, 339, 135924. [CrossRef]

44. Kafi, A.K.M.; Alim, S.; Jose, R.; Yusoff, M.M. Fabrication of a glucose oxidase/multiporous tin-oxide nanofiber film on Prussian blue-modified gold electrode for biosensing. J. Electroanal. Chem. 2019, 852, 113550. [CrossRef]

45. Cao, L.; Han, G.-C.; Xiao, H.; Chen, Z.; Fang, C. A novel 3D paper-based microfluidic electrochemical glucose biosensor based on rGO-TEPA/PB sensitive film. Anal. Chim. Acta 2020, 1096, 34-43. [CrossRef] [PubMed]

46. Kim, J.; Jeerapan, I.; Imani, S.; Cho, T.N.; Bandodkar, A.; Cinti, S.; Mercier, P.P.; Wang, J. Noninvasive Alcohol Monitoring Using a Wearable Tattoo-Based Iontophoretic-Biosensing System. ACS Sens. 2016, 1, 1011-1019. [CrossRef]

47. Cinti, S.; Basso, M.; Moscone, D.; Arduini, F. A paper-based nanomodified electrochemical biosensor for ethanol detection in beers. Anal. Chim. Acta 2017, 960, 123-130. [CrossRef] [PubMed]

48. Valiūnienè, A.; Virbickas, P.; Rekertaitè, A.; Ramanavičius, A. Amperometric Glucose Biosensor Based on Titanium Electrode Modified with Prussian Blue Layer and Immobilized Glucose Oxidase. J. Electrochem. Soc. 2017, 164, B781-B784. [CrossRef]

49. Karyakin, A.A.; Karyakina, E.E.; Gorton, L. On the mechanism of $\mathrm{H}_{2} \mathrm{O}_{2}$ reduction at Prussian Blue modified electrodes. Electrochem. Commun. 1999, 1, 78-82. [CrossRef]

50. Matos-Peralta, Y.; Antuch, M. Review_Prussian Blue and Its Analogs as Appealing Materials for Electrochemical Sensing and Biosensing. J. Electrochem. Soc. 2019, 167, 037510. [CrossRef]

51. Ricci, F.; Amine, A.; Palleschi, G.; Moscone, D. Prussian Blue based screen printed biosensors with improved characteristics of long-term lifetime and pH stability. Biosens. Bioelectron. 2003, 18, 165-174. [CrossRef]

52. Stilwell, D.E.; Park, K.H.; Miles, M.H. Electrochemical studies of the factors influencing the cycle stability of Prussian Blue films. J. Appl. Electrochem. 1992, 22, 325-331. [CrossRef]

53. Haghighi, B.; Varma, S.; Alizadeh Sh, F.M.; Yigzaw, Y.; Gorton, L. Prussian blue modified glassy carbon electrodes-Study on operational stability and its application as a sucrose biosensor. Talanta 2004, 64, 3-12. [CrossRef]

54. Sehit, E.; Altintas, Z. Significance of nanomaterials in electrochemical glucose sensors: An updated review (2016-2020). Biosens. Bioelectron. 2020, 159, 112165. [CrossRef] 
55. Karimi-Maleh, H.; Karimi, F.; FallahShojaei, A.; Tabatabaeian, K.; Arshadi, M.; Rezapour, M. Metal-based Nanoparticles as Conductive Mediators in Electrochemical Sensors: A Mini Review. Curr. Anal. Chem. 2019, 15, 136-142. [CrossRef]

56. Lim, S.A.; Ahmed, M.U. Electrochemical immunosensors and their recent nanomaterial-based signal amplification strategies: A review. RSC Adv. 2016, 6, 24995-25014. [CrossRef]

57. Han, L.; Tang, P.; Reyes-Carmona, Á.; Rodríguez-García, B.; Torréns, M.; Morante, J.R.; Arbiol, J.; Galan-Mascaros, J.R. Enhanced Activity and Acid pH Stability of Prussian Blue-type Oxygen Evolution Electrocatalysts Processed by Chemical Etching. J. Am. Chem. Soc. 2016, 138, 16037-16045. [CrossRef] [PubMed]

58. de Castro, L.F.; de Freitas, S.V.; Duarte, L.C.; de Souza, J.A.C.; Paixão, T.R.L.C.; Coltro, W.K.T. Salivary diagnostics on paper microfluidic devices and their use as wearable sensors for glucose monitoring. Anal. Bioanal. Chem. 2019, 411, 4919-4928. [CrossRef] [PubMed]

59. Gug, I.T.; Tertis, M.; Hosu, O.; Cristea, C. Salivary biomarkers detection: Analytical and immunological methods overview. TracTrends Anal. Chem. 2019, 113, 301-316. [CrossRef]

60. Nightingale, A.M.; Leong, C.L.; Burnish, R.A.; Hassan, S.-u.; Zhang, Y.; Clough, G.F.; Boutelle, M.G.; Voegeli, D.; Niu, X. Monitoring biomolecule concentrations in tissue using a wearable droplet microfluidic-based sensor. Nat. Commun. 2019, 10, 2741. [CrossRef]

61. Kim, K.O.; Kim, G.J.; Kim, J.H. A cellulose/ $\beta$-cyclodextrin nanofiber patch as a wearable epidermal glucose sensor. RSC Adv. 2019, 9, 22790-22794. [CrossRef]

62. Tai, L.-C.; Liaw, T.S.; Lin, Y.; Nyein, H.Y.Y.; Bariya, M.; Ji, W.; Hettick, M.; Zhao, C.; Zhao, J.; Hou, L.; et al. Wearable Sweat Band for Noninvasive Levodopa Monitoring. Nano Lett. 2019, 19, 6346-6351. [CrossRef]

63. Lee, H.-B.; Meeseepong, M.; Trung, T.Q.; Kim, B.-Y.; Lee, N.-E. A wearable lab-on-a-patch platform with stretchable nanostructured biosensor for non-invasive immunodetection of biomarker in sweat. Biosens. Bioelectron. 2020, 156, 112133. [CrossRef]

64. Panchbhai, A.S. Correlation of salivary glucose level with blood glucose level in diabetes mellitus. J. Oral Maxillofac. Res. 2012, 3, e3. [CrossRef]

65. Gupta, S.; Sandhu, S.V.; Bansal, H.; Sharma, D. Comparison of Salivary and Serum Glucose Levels in Diabetic Patients. J. Diabetes Sci. Technol. 2015, 9, 91-96. [CrossRef] [PubMed]

66. Savikj, M.; Gabriel, B.M.; Alm, P.S.; Smith, J.; Caidahl, K.; Björnholm, M.; Fritz, T.; Krook, A.; Zierath, J.R.; Wallberg-Henriksson, $\mathrm{H}$. Afternoon exercise is more efficacious than morning exercise at improving blood glucose levels in individuals with type 2 diabetes: A randomised crossover trial. Diabetologia 2019, 62, 233-237. [CrossRef]

67. Badugu, R.; Lakowicz, J.R.; Geddes, C.D. Ophthalmic Glucose Monitoring Using Disposable Contact Lenses-A Review. J. Fluoresc. 2004, 14, 617-633. [CrossRef] [PubMed]

68. Bruen, D.; Delaney, C.; Florea, L.; Diamond, D. Glucose Sensing for Diabetes Monitoring: Recent Developments. Sensors 2017, 17, 1866. [CrossRef] [PubMed]

69. Karpova, E.V.; Shcherbacheva, E.V.; Galushin, A.A.; Vokhmyanina, D.V.; Karyakina, E.E.; Karyakin, A.A. Noninvasive Diabetes Monitoring through Continuous Analysis of Sweat Using Flow-Through Glucose Biosensor. Anal. Chem. 2019, 91, 3778-3783. [CrossRef] [PubMed]

70. Hayford, J.T.; Weydert, J.A.; Thompson, R.G. Validity of Urine Glucose Measurements for Estimating Plasma Glucose Concentration. Diabetes Care 1983, 6, 40. [CrossRef] [PubMed]

71. Lee, H.; Song, C.; Hong, Y.S.; Kim, M.S.; Cho, H.R.; Kang, T.; Shin, K.; Choi, S.H.; Hyeon, T.; Kim, D.-H. Wearable/disposable sweat-based glucose monitoring device with multistage transdermal drug delivery module. Sci. Adv. 2017, 3, e1601314. [CrossRef]

72. Xiao, J.; Liu, Y.; Su, L.; Zhao, D.; Zhao, L.; Zhang, X. Microfluidic Chip-Based Wearable Colorimetric Sensor for Simple and Facile Detection of Sweat Glucose. Anal. Chem. 2019, 91, 14803-14807. [CrossRef]

73. Harvey, C.J.; LeBouf, R.F.; Stefaniak, A.B. Formulation and stability of a novel artificial human sweat under conditions of storage and use. Toxicol. In Vitro 2010, 24, 1790-1796. [CrossRef]

74. Juvenile Diabetes Research Foundation Continuous Glucose Monitoring Study Group. Variation of interstitial glucose measurements assessed by continuous glucose monitors in healthy, nondiabetic individuals. Diabetes Care 2010, 33, 1297-1299. [CrossRef]

75. Makaram, P.; Owens, D.; Aceros, J. Trends in Nanomaterial-Based Non-Invasive Diabetes Sensing Technologies. Diagnostics 2014, 4, 27-46. [CrossRef] [PubMed] 
76. Robinson, S.; Dhanlaksmi, N. Photonic crystal based biosensor for the detection of glucose concentration in urine. Photonic Sens. 2017, 7, 11-19. [CrossRef]

77. Coyle, V.E.; Kandjani, A.E.; Field, M.R.; Hartley, P.; Chen, M.; Sabri, Y.M.; Bhargava, S.K. $\mathrm{Co}_{3} \mathrm{O}_{4}$ needles on $\mathrm{Au}$ honeycomb as a non-invasive electrochemical biosensor for glucose in saliva. Biosens. Bioelectron. 2019, 141, 111479. [CrossRef] [PubMed]

78. Jurysta, C.; Bulur, N.; Oguzhan, B.; Satman, I.; Yilmaz, T.M.; Malaisse, W.J.; Sener, A. Salivary glucose concentration and excretion in normal and diabetic subjects. J. Biomed. Biotechnol. 2009, 2009, 430426. [CrossRef]

79. Khan, S.U. Implantable Non-Enzymatic Electrochemical Glucose Sensor. U.S. Patent US 5,469,846, 28 November 1995.

80. Thekkedath, S.B.G.; Thiagarajan, R.; Nair, B.G. Non-Enzymatic Glucose Sensor. U.S. Patent US 10,330,634, 25 June 2019.

81. Hwang, D.-W.; Lee, S.; Seo, M.; Chung, T.D. Recent advances in electrochemical non-enzymatic glucose sensors-A review. Anal. Chim. Acta 2018, 1033, 1-34. [CrossRef] [PubMed]

82. Lopa, N.S.; Rahman, M.M.; Ahmed, F.; Ryu, T.; Lei, J.; Choi, I.; Kim, D.H.; Lee, Y.H.; Kim, W. A chemically and electrochemically stable, redox-active and highly sensitive metal azolate framework for non-enzymatic electrochemical detection of glucose. J. Electroanal. Chem. 2019, 840, 263-271. [CrossRef]

83. Viswanathan, P.; Kim, Y.J.; Hong, J.D. Nanoporous Silver Submicrocubes Layer by Layer Encapsulated with Polyelectrolyte Films: Nonenzymatic Catalysis for Glucose Monitoring. Langmuir 2020, 36, 3452-3460. [CrossRef]

84. Li, Y.; Shi, L.; Cai, X.; Zhao, H.; Niu, X.; Lan, M. Construction of non-enzymatic sensor based on porous carbon matrix loaded with $\mathrm{Pt}$ and Co nanoparticles for real-time monitoring of cellular superoxide anions. Electrochim. Acta 2019, 294, 304-311. [CrossRef]

85. Bae, C.W.; Toi, P.T.; Kim, B.Y.; Lee, W.I.; Lee, H.B.; Hanif, A.; Lee, E.H.; Lee, N.-E. Fully Stretchable Capillary Microfluidics-Integrated Nanoporous Gold Electrochemical Sensor for Wearable Continuous Glucose Monitoring. ACS Appl. Mater. Interfaces 2019, 11, 14567-14575. [CrossRef]

86. Zhao, Y.; Zhai, Q.; Dong, D.; An, T.; Gong, S.; Shi, Q.; Cheng, W. Highly Stretchable and Strain-Insensitive Fiber-Based Wearable Electrochemical Biosensor to Monitor Glucose in the Sweat. Anal. Chem. 2019, 91, 6569-6576. [CrossRef]

87. Sedighi, A.; Montazer, M.; Mazinani, S. Synthesis of wearable and flexible NiP0.1-SnOx/PANI/CuO/cotton towards a non-enzymatic glucose sensor. Biosens. Bioelectron. 2019, 135, 192-199. [CrossRef] [PubMed]

88. Zhai, Q.; Yap, L.W.; Wang, R.; Gong, S.; Guo, Z.; Liu, Y.; Lyu, Q.; Wang, J.; Simon, G.P.; Cheng, W. Vertically Aligned Gold Nanowires as Stretchable and Wearable Epidermal Ion-Selective Electrode for Noninvasive Multiplexed Sweat Analysis. Anal. Chem. 2020, 92, 4647-4655. [CrossRef] [PubMed]

89. Liu, H.; Li, H.; Ying, T.; Sun, K.; Qin, Y.; Qi, D. Amperometric biosensor sensitive to glucose and lactose based on co-immobilization of ferrocene, glucose oxidase, $\beta$-galactosidase and mutarotase in $\beta$-cyclodextrin polymer. Anal. Chim. Acta 1998, 358, 137-144. [CrossRef]

90. Zhu, Y.; Wang, Y.; Kang, K.; Lin, Y.; Guo, W.; Wang, J. A nickel-cobalt bimetallic phosphide nanocage as an efficient electrocatalyst for nonenzymatic sensing of glucose. Microchim. Acta 2020, 187, 100. [CrossRef]

91. Karimi-Maleh, H.; Cellat, K.; Arıkan, K.; Savk, A.; Karimi, F.; Şen, F. Palladium-Nickel nanoparticles decorated on Functionalized-MWCNT for high precision non-enzymatic glucose sensing. Mater. Chem. Phys. 2020, 250, 123042. [CrossRef]

92. Rinaldi, A.L.; Bonetto, M.C.; Sobral, S.; Carballo, R. Evaluation of the synergistic effects of a novel organic-inorganic nickel hybrid nanocomposite as electrocatalyst toward glucose oxidation. J. Electroanal. Chem. 2020, 863, 114039. [CrossRef]

93. Zhang, L.; Liu, J.; Fu, Z.; Qi, L. A Wearable Biosensor Based on Bienzyme Gel-Membrane for Sweat Lactate Monitoring by Mounting on Eyeglasses. J. Nanosci. Nanotechnol. 2020, 20, 1495-1503. [CrossRef]

94. Ruff, A. Redox polymers in bioelectrochemistry: Common playgrounds and novel concepts. Curr. Opin. Electrochem. 2017, 5, 66-73. [CrossRef]

95. Hickey, D.P.; Reid, R.C.; Milton, R.D.; Minteer, S.D. A self-powered amperometric lactate biosensor based on lactate oxidase immobilized in dimethylferrocene-modified LPEI. Biosens. Bioelectron. 2016, 77, $26-31$. [CrossRef]

96. Jeerapan, I.; Poorahong, S. Review-Flexible and Stretchable Electrochemical Sensing Systems: Materials, Energy Sources, and Integrations. J. Electrochem. Soc. 2020, 167, 037573. [CrossRef] 
97. Jeerapan, I.; Sempionatto, J.R.; Pavinatto, A.; You, J.-M.; Wang, J. Stretchable biofuel cells as wearable textile-based self-powered sensors. J. Mater. Chem. A 2016, 4, 18342-18353. [CrossRef] [PubMed]

98. Guan, H.; Zhong, T.; He, H.; Zhao, T.; Xing, L.; Zhang, Y.; Xue, X. A self-powered wearable sweat-evaporationbiosensing analyzer for building sports big data. Nano Energy 2019, 59, 754-761. [CrossRef]

99. Lin, K.-C.; Muthukumar, S.; Prasad, S. Flex-GO (Flexible graphene oxide) sensor for electrochemical monitoring lactate in low-volume passive perspired human sweat. Talanta 2020, 214, 120810. [CrossRef] [PubMed]

100. Nagamine, K.; Mano, T.; Nomura, A.; Ichimura, Y.; Izawa, R.; Furusawa, H.; Matsui, H.; Kumaki, D.; Tokito, S. Noninvasive Sweat-Lactate Biosensor Emplsoying a Hydrogel-Based Touch Pad. Sci. Rep. 2019, 9, 10102. [CrossRef]

101. Bollella, P.; Sharma, S.; Cass, A.E.G.; Antiochia, R. Microneedle-based biosensor for minimally-invasive lactate detection. Biosens. Bioelectron. 2019, 123, 152-159. [CrossRef] [PubMed]

102. Payne, M.E.; Zamarayeva, A.; Pister, V.I.; Yamamoto, N.A.D.; Arias, A.C. Printed, Flexible Lactate Sensors: Design Considerations Before Performing On-Body Measurements. Sci. Rep. 2019, 9, 13720. [CrossRef]

103. Jeerapan, I. Wearable Skin-Worn Enzyme-Based Electrochemical Devices: Biosensing, Energy Harvesting, and Self-Powered Sensing. In Wearable Devices-the Big Wave of Innovation; IntechOpen: London, UK, 2019. [CrossRef]

104. Zhao, L.; Wen, Z.; Jiang, F.; Zheng, Z.; Lu, S. Silk/polyols/GOD microneedle based electrochemical biosensor for continuous glucose monitoring. RSC Adv. 2020, 10, 6163-6171. [CrossRef]

105. Bollella, P.; Sharma, S.; Cass, A.E.G.; Antiochia, R. Minimally-invasive Microneedle-based Biosensor Array for Simultaneous Lactate and Glucose Monitoring in Artificial Interstitial Fluid. Electroanalysis 2019, 31, 374-382. [CrossRef]

106. Gao, J.; Huang, W.; Chen, Z.; Yi, C.; Jiang, L. Simultaneous detection of glucose, uric acid and cholesterol using flexible microneedle electrode array-based biosensor and multi-channel portable electrochemical analyzer. Sens. Actuators B Chem. 2019, 287, 102-110. [CrossRef]

107. Hang, T.; Xiao, S.; Yang, C.; Li, X.; Guo, C.; He, G.; Li, B.; Yang, C.; Chen, H.-j.; Liu, F.; et al. Hierarchical graphene/nanorods-based $\mathrm{H}_{2} \mathrm{O}_{2}$ electrochemical sensor with self-cleaning and anti-biofouling properties. Sens. Actuators B Chem. 2019, 289, 15-23. [CrossRef]

108. Erathodiyil, N.; Chan, H.-M.; Wu, H.; Ying, J.Y. Zwitterionic polymers and hydrogels for antibiofouling applications in implantable devices. Mater. Today 2020. [CrossRef]

109. Means, A.K.; Dong, P.; Clubb, F.J.; Friedemann, M.C.; Colvin, L.E.; Shrode, C.A.; Coté, G.L.; Grunlan, M.A. A self-cleaning, mechanically robust membrane for minimizing the foreign body reaction: Towards extending the lifetime of sub-Q glucose biosensors. J. Mater. Sci. Mater. Med. 2019, 30, 79. [CrossRef]

110. Lyu, Y.; Gan, S.; Bao, Y.; Zhong, L.; Xu, J.; Wang, W.; Liu, Z.; Ma, Y.; Yang, G.; Niu, L. Solid-Contact Ion-Selective Electrodes: Response Mechanisms, Transducer Materials and Wearable Sensors. Membranes 2020, 10, 128. [CrossRef] [PubMed]

111. Yang, X.; Cheng, H. Recent Developments of Flexible and Stretchable Electrochemical Biosensors. Micromachines 2020, 11, 243. [CrossRef] [PubMed]

112. Wang, S.; Bai, Y.; Yang, X.; Liu, L.; Li, L.; Lu, Q.; Li, T.; Zhang, T. Highly stretchable potentiometric ion sensor based on surface strain redistributed fiber for sweat monitoring. Talanta 2020, 214, 120869. [CrossRef]

113. Choi, S.-J.; Savagatrup, S.; Kim, Y.; Lang, J.H.; Swager, T.M. Precision pHSensor Based on WO3 Nanofiber-Polymer Composites and Differential Amplification. ACS Sens. 2019, 4, 2593-2598. [CrossRef] [PubMed]

114. Singh, K.; Lou, B.-S.; Her, J.-L.; Pang, S.-T.; Pan, T.-M. Super Nernstian pH response and enzyme-free detection of glucose using sol-gel derived RuOx on PET flexible-based extended-gate field-effect transistor. Sens. Actuators B Chem. 2019, 298, 126837. [CrossRef]

115. Yoon, J.H.; Kim, S.-M.; Park, H.J.; Kim, Y.K.; Oh, D.X.; Cho, H.-W.; Lee, K.G.; Hwang, S.Y.; Park, J.; Choi, B.G. Highly self-healable and flexible cable-type $\mathrm{pH}$ sensors for real-time monitoring of human fluids. Biosens. Bioelectron. 2020, 150, 111946. [CrossRef]

116. Liang, Z.; Zhang, J.; Wu, C.; Hu, X.; Lu, Y.; Wang, G.; Yu, F.; Zhang, X.; Wang, Y. Flexible and self-healing electrochemical hydrogel sensor with high efficiency toward glucose monitoring. Biosens. Bioelectron. 2020, 155, 112105. [CrossRef]

117. Yang, Y.; Song, Y.; Bo, X.; Min, J.; Pak, O.S.; Zhu, L.; Wang, M.; Tu, J.; Kogan, A.; Zhang, H.; et al. A laser-engraved wearable sensor for sensitive detection of uric acid and tyrosine in sweat. Nat. Biotechnol. 2020, 38, $217-224$. [CrossRef] 
118. Cheng, X.; Wang, B.; Zhao, Y.; Hojaiji, H.; Lin, S.; Shih, R.; Lin, H.; Tamayosa, S.; Ham, B.; Stout, P.; et al. A Mediator-Free Electroenzymatic Sensing Methodology to Mitigate Ionic and Electroactive Interferents' Effects for Reliable Wearable Metabolite and Nutrient Monitoring. Adv. Funct. Mater. 2019, 1908507. [CrossRef]

119. Cordeiro, C.A.; de Vries, M.G.; Cremers, T.I.F.H.; Westerink, B.H.C. The role of surface availability in membrane-induced selectivity for amperometric enzyme-based biosensors. Sens. Actuators B Chem. 2016, 223, 679-688. [CrossRef]

120. Soldatkina, O.V.; Kucherenko, I.S.; Pyeshkova, V.M.; Alekseev, S.A.; Soldatkin, O.O.; Dzyadevych, S.V. Improvement of amperometric transducer selectivity using nanosized phenylenediamine films. Nanoscale Res. Lett. 2017, 12, 594. [CrossRef] [PubMed]

121. Guerrieri, A.; Ciriello, R.; Crispo, F.; Bianco, G. Detection of choline in biological fluids from patients on haemodialysis by an amperometric biosensor based on a novel anti-interference bilayer. Bioelectrochemistry 2019, 129, 135-143. [CrossRef]

122. An, Q.; Gan, S.; Xu, J.; Bao, Y.; Wu, T.; Kong, H.; Zhong, L.; Ma, Y.; Song, Z.; Niu, L. A multichannel electrochemical all-solid-state wearable potentiometric sensor for real-time sweat ion monitoring. Electrochem. Commun. 2019, 107, 106553. [CrossRef]

123. Xu, H.; Lu, Y.F.; Xiang, J.X.; Zhang, M.K.; Zhao, Y.J.; Xie, Z.Y.; Gu, Z.Z. A multifunctional wearable sensor based on a graphene/inverse opal cellulose film for simultaneous, in situ monitoring of human motion and sweat. Nanoscale 2018, 10, 2090-2098. [CrossRef]

124. Jiang, Y.; Pan, K.; Leng, T.; Hu, Z. Smart Textile Integrated Wireless Powered Near Field Communication (NFC) Body Temperature and Sweat Sensing System. IEEE J. Electromagn. RF Microw. Med. Biol. 2019. [CrossRef]

125. Khan, S.U.; Anderson, B.D.; Heil, G.L.; Liang, S.; Gray, G.C. A Systematic Review and Meta-Analysis of the Seroprevalence of Influenza A(H9N2) Infection Among Humans. J. Infect. Dis. 2015, 212, 562-569. [CrossRef]

126. Sohrabi, C.; Alsafi, Z.; O’Neill, N.; Khan, M.; Kerwan, A.; Al-Jabir, A.; Iosifidis, C.; Agha, R. World Health Organization declares global emergency: A review of the 2019 novel coronavirus (COVID-19). Int. J. Surg. 2020, 76, 71-76. [CrossRef]

127. Shereen, M.A.; Khan, S.; Kazmi, A.; Bashir, N.; Siddique, R. COVID-19 infection: Origin, transmission, and characteristics of human coronaviruses. J. Adv. Res. 2020, 24, 91-98. [CrossRef]

128. Lupia, T.; Scabini, S.; Mornese Pinna, S.; Di Perri, G.; De Rosa, F.G.; Corcione, S. 2019 novel coronavirus (2019-nCoV) outbreak: A new challenge. J. Glob. Antimicrob. Resist. 2020, 21, 22-27. [CrossRef] [PubMed]

129. Li, H.; Liu, L.; Zhang, D.; Xu, J.; Dai, H.; Tang, N.; Su, X.; Cao, B. SARS-CoV-2 and viral sepsis: Observations and hypotheses. Lancet 2020, 395, 1517-1520. [CrossRef]

130. Newton, P.N.; Bond, K.C.; Adeyeye, M.; Antignac, M.; Ashenef, A.; Awab, G.R.; Babar, Z.-U.-D.; Bannenberg, W.J.; Bond, K.C.; Bower, J.; et al. COVID-19 and risks to the supply and quality of tests, drugs, and vaccines. Lancet Glob. Health 2020, 8, e754-e755. [CrossRef]

131. Angela, C.; Stefan, M.; Ai Ee, L.; Suok Kai, C. Influenza-associated Deaths in Tropical Singapore. Emerg. Infect. Dis. J. 2006, 12, 114. [CrossRef]

132. Barro, R.J.; Ursúa, J.F.; Weng, J. The Coronavirus and the Great Influenza Pandemic: Lessons from the "Spanish Flu" for the Coronavirus's Potential Effects on Mortality and Economic Activity; 0898-2937; National Bureau of Economic Research: 2020. Available online: https://www.nber.org/papers/w26866 (accessed on 5 June 2020).

133. Bhardwaj, J.; Chaudhary, N.; Kim, H.; Jang, J. Subtyping of influenza A H1N1 virus using a label-free electrochemical biosensor based on the DNA aptamer targeting the stem region of HA protein. Anal. Chim. Acta 2019, 1064, 94-103. [CrossRef] [PubMed]

134. Moulick, A.; Richtera, L.; Milosavljevic, V.; Cernei, N.; Haddad, Y.; Zitka, O.; Kopel, P.; Heger, Z.; Adam, V. Advanced nanotechnologies in avian influenza: Current status and future trends-A review. Anal. Chim. Acta 2017, 983, 42-53. [CrossRef]

135. Banga, I.; Tyagi, R.; Shahdeo, D.; Gandhi, S. Chapter 1-Biosensors and Their Application for the Detection of Avian Influenza Virus. In Nanotechnology in Modern Animal Biotechnology; Maurya, P.K., Singh, S., Eds.; Elsevier: London, UK, 2019; pp. 1-16. [CrossRef]

136. Kinnamon, D.S.; Krishnan, S.; Brosler, S.; Sun, E.; Prasad, S. Screen Printed Graphene Oxide Textile Biosensor for Applications in Inexpensive and Wearable Point-of-Exposure Detection of Influenza for At-Risk Populations. J. Electrochem. Soc. 2018, 165, B3084-B3090. [CrossRef] 
137. Lee, T.; Park, S.Y.; Jang, H.; Kim, G.-H.; Lee, Y.; Park, C.; Mohammadniaei, M.; Lee, M.-H.; Min, J. Fabrication of electrochemical biosensor consisted of multi-functional DNA structure/porous au nanoparticle for avian influenza virus (H5N1) in chicken serum. Mater. Sci. Eng. C 2019, 99, 511-519. [CrossRef]

138. Kwon, J.; Lee, Y.; Lee, T.; Ahn, J.-H. Aptamer-Based Field-Effect Transistor for Detection of Avian Influenza Virus in Chicken Serum. Anal. Chem. 2020, 92, 5524-5531. [CrossRef]

139. Joshi, S.R.; Sharma, A.; Kim, G.-H.; Jang, J. Low cost synthesis of reduced graphene oxide using biopolymer for influenza virus sensor. Mater. Sci. Eng. C 2020, 108, 110465. [CrossRef]

140. Layqah, L.A.; Eissa, S. An electrochemical immunosensor for the corona virus associated with the Middle East respiratory syndrome using an array of gold nanoparticle-modified carbon electrodes. Microchim. Acta 2019, 186, 224. [CrossRef] [PubMed]

141. Harder, T.C.; Buda, S.; Hengel, H.; Beer, M.; Mettenleiter, T.C. Poultry food products—A source of avian influenza virus transmission to humans? Clin. Microbiol. Infect. 2016, 22, 141-146. [CrossRef] [PubMed]

142. Li, Y.-T.; Linster, M.; Mendenhall, I.H.; Su, Y.C.F.; Smith, G.J.D. Avian influenza viruses in humans: Lessons from past outbreaks. Br. Med. Bull. 2019, 132, 81-95. [CrossRef] [PubMed]

143. Kosman, J.; Juskowiak, B. Bioanalytical Application of Peroxidase-Mimicking DNAzymes: Status and Challenges. In Catalytically Active Nucleic Acids; Seitz, H., Stahl, F., Walter, J.-G., Eds.; Springer International Publishing: Cham, Switzerland, 2020; pp. 59-84. [CrossRef]

144. Zhang, R.; Olin, H. Porous Gold Films-A Short Review on Recent Progress. Materials 2014, 7, $3834-3854$. [CrossRef] [PubMed]

145. Rozenblum, G.T.; Pollitzer, I.G.; Radrizzani, M. Challenges in Electrochemical Aptasensors and Current Sensing Architectures Using Flat Gold Surfaces. Chemosensors 2019, 7, 57. [CrossRef]

146. Putzbach, W.; Ronkainen, N.J. Immobilization Techniques in the Fabrication of Nanomaterial-Based Electrochemical Biosensors: A Review. Sensors 2013, 13, 4811-4840. [CrossRef]

147. Shehata, M.M.; Gomaa, M.R.; Ali, M.A.; Kayali, G. Middle East respiratory syndrome coronavirus: A comprehensive review. Front. Med. 2016, 10, 120-136. [CrossRef]

148. Haji-Hashemi, H.; Safarnejad, M.R.; Norouzi, P.; Ebrahimi, M.; Shahmirzaie, M.; Ganjali, M.R. Simple and effective label free electrochemical immunosensor for Fig mosaic virus detection. Anal. Biochem. 2019, 566, 102-106. [CrossRef]

149. Soares, R.R.G.; Neumann, F.; Caneira, C.R.F.; Madaboosi, N.; Ciftci, S.; Hernández-Neuta, I.; Pinto, I.F.; Santos, D.R.; Chu, V.; Russom, A.; et al. Silica bead-based microfluidic device with integrated photodiodes for the rapid capture and detection of rolling circle amplification products in the femtomolar range. Biosens. Bioelectron. 2019, 128, 68-75. [CrossRef]

150. Zhu, H.; Fohlerová, Z.; Pekárek, J.; Basova, E.; Neužil, P. Recent advances in lab-on-a-chip technologies for viral diagnosis. Biosens. Bioelectron. 2020, 153, 112041. [CrossRef]

151. Kong, M.; Li, Z.; Wu, J.; Hu, J.; Sheng, Y.; Wu, D.; Lin, Y.; Li, M.; Wang, X.; Wang, S. A wearable microfluidic device for rapid detection of HIV-1 DNA using recombinase polymerase amplification. Talanta 2019, 205, 120155. [CrossRef]

152. Yu, W.; Kong, X.; Gu, C.; Gai, P.; Li, F. Ultrasensitive self-powered biosensors with visual self-checking function for pathogenic bacteria detection. Sens. Actuators B Chem. 2020, 307, 127618. [CrossRef]

153. Sekretaryova, A. Chapter 4-Powering wearable bioelectronic devices. In Wearable Bioelectronics; Parlak, O., Salleo, A., Turner, A., Eds.; Elsevier: London, UK, 2020; pp. 89-132. [CrossRef]

154. Jeerapan, I.; Sempionatto, J.R.; Wang, J. On-Body Bioelectronics: Wearable Biofuel Cells for Bioenergy Harvesting and Self-Powered Biosensing. Adv. Funct. Mater. 2019, 1906243. [CrossRef]

155. Yang, B.; Kong, J.; Fang, X. Bandage-like wearable flexible microfluidic recombinase polymerase amplification sensor for the rapid visual detection of nucleic acids. Talanta 2019, 204, 685-692. [CrossRef] [PubMed]

156. Promphet, N.; Hinestroza, J.P.; Rattanawaleedirojn, P.; Soatthiyanon, N.; Siralertmukul, K.; Potiyaraj, P.; Rodthongkum, N. Cotton thread-based wearable sensor for non-invasive simultaneous diagnosis of diabetes and kidney failure. Sens. Actuators B Chem. 2020, 321, 128549. [CrossRef]

157. Weng, X.; Neethirajan, S. Immunosensor Based on Antibody-Functionalized MoS2 for Rapid Detection of Avian Coronavirus on Cotton Thread. IEEE Sens. J. 2018, 18, 4358-4363. [CrossRef] 